\title{
Liver stiffness: a novel parameter for the diagnosis of liver disease
}

This article was published in the following Dove Press journal:

Hepatic Medicine: Evidence and Research

24 May 2010

Number of times this article has been viewed

\author{
Sebastian Mueller' \\ Laurent Sandrin² \\ 'Department of Medicine and Center \\ for Alcohol Research, Liver Disease \\ and Nutrition, Salem Medical Center, \\ University of Heidelberg, Heidelberg, \\ Germany; ${ }^{2}$ Echosens, Department of \\ Research and Development, Paris, \\ France
}

\begin{abstract}
The noninvasive quantitation of liver stiffness (LS) by ultrasound based transient elastography using FibroScan ${ }^{\circledR}$ has revolutionized the diagnosis of liver diseases, namely liver cirrhosis. Alternative techniques such as acoustic radiation impulse frequency imaging or magnetic resonance elastography are currently under investigation. LS is an excellent surrogate marker of advanced fibrosis (F3) and cirrhosis (F4) outscoring all previous noninvasive approaches to detect cirrhosis. LS values below $6 \mathrm{kPa}$ are considered as normal and exclude ongoing liver disease. LS of 8 and $12.5 \mathrm{kPa}$ represent generally accepted cut-off values for F3 and F4 fibrosis. LS highly correlates with portal pressure, and esophageal varices are likely at values $>20 \mathrm{kPa}$. Many other factors may also increase LS such as hepatic infiltration with tumor cells, mast cells (mastocytosis), inflammatory cells (all forms of hepatitis) or amyloidosis. In addition, LS is directly correlated with the venous pressure (eg, during liver congestion) and is increased during mechanic cholestasis. Thus, LS should always be interpreted in the context of clinical, imaging and laboratory findings. Finally, LS has helped to better understand the molecular mechanisms underlying liver fibrosis. The novel pressure-stiffness-fibrosis sequence hypothesis is introduced.
\end{abstract}

Keywords: liver stiffness, fibrosis, liver disease, transient elastography

\section{Introduction}

All chronic liver diseases whether of toxic, genetic, autoimmune or infectious origin undergo typical histological changes that ultimately lead to fibrosis/cirrhosis, and the excess deposition of matrix. Liver cirrhosis can rapidly decompensate and has a high mortality rate. Patients with cirrhosis suffer from a decreasing hepatic capacity to metabolize and synthesize proteins, peptides and hormones. In addition, progression of fibrosis and regenerating nodules cause an increased vascular portocaval resistance with portal hypertension and an increased hepatic venous pressure gradient (HVPG) of $>10 \mathrm{~mm} \mathrm{Hg}$. Portal hypertension finally leads to ascites, and vascular collaterals will develop such as esophageal varices. Most patients suffering from cirrhosis eventually die from complications such as spontaneous bacterial peritonitis, variceal bleeding, liver failure or hepatocellular carcinoma (HCC). Especially compensated liver cirrhosis without clinical signs such as spider nevi, encephalopathy, icterus, or ascites is difficult to diagnose. Such patients typically do not show specific symptoms. This is also one important reason why no valid and reliable prevalence data are available for cirrhosis for many countries, although cirrhosis is a major mortality cause in developed countries at the age of 40-60 years. 
Many techniques have been explored in the last decades to allow an early and reliable diagnosis of cirrhosis (see Figure 1). These include both invasive but also noninvasive approaches. Liver biopsy is still considered the gold standard for assessing hepatic cirrhosis. However, it is an invasive procedure, with rare but potentially life-threatening complications. ${ }^{1}$ In addition, the accuracy of liver biopsy in assessing fibrosis is limited owing to sampling error (reaching up to $30 \%$ ) and interobserver variability. ${ }^{2-6}$ Other invasive procedures such as laparoscopy and endoscopy are not very sensitive. Likewise, conventional imaging techniques such as ultrasound, magnetic resonance imaging (MRI) and computer tomography (CT) are noninvasive but absolute signs of cirrhosis such as collaterals or nodular aspect of the liver surface are required, rendering these methods rather insensitive. Many efforts have been invested to identify serum markers that allow the diagnosis of cirrhosis from a simple blood test. ${ }^{7}$ Unfortunately, although markers such as serum collagen or hyaluron reflect profibrogenic activity, they do not correlate with the absolute amount of matrix deposited in the liver.

Liver cirrhosis per se causes a typical induration of the liver that is sometimes clearly palpable. In fact, palpation of the liver has been used by physicians for centuries as the only valid bedside test to diagnose cirrhosis. Thus, it has been a question of time to develop sophisticated physical methods to truly quantify liver stiffness (LS). The first such approach has been successfully introduced by Sandrin and coworkers in $2003 .{ }^{8}$ Meanwhile, many studies on chronic liver diseases have proven that measurement of LS is a rapid and excellent screening test for liver cirrhosis. Alternative approaches are currently explored either based on competing ultrasound or MRI methods, and the future will show which technique will prevail in which clinical setting.

On the other hand, LS has been introduced to the field of hepatology as a novel objective physical parameter that can be followed up as compared to, for example, temperature. Like body temperature, we have learnt in a rather short time that LS is not only determined by the degree of fibrosis but also other clinical settings such as inflammation, cholestasis and liver congestions. This review, therefore, is designed to briefly update the reader on the present knowledge of LS. After an overview about technical aspects and alternative methods, basic conditions are discussed that influence LS. Algorithms are presented on how to use LS values in clinical practices, to consider pitfalls. In addition, the novel pressurestiffness-fibrosis sequence hypothesis is introduced and briefly discussed that could stimulate the intensive search to identify the molecular mechanisms underlying liver fibrosis. Finally, open LS-related questions are defined that should be addressed by future clinical and basic research studies.

\section{Pathophysiology of liver stiffness Liver stiffness - definition}

Going through the theory of elasticity is far beyond the scope of this review. However some basic notions are useful to

$\begin{array}{ll}\text { Invasive Noninvasive } & \end{array}$

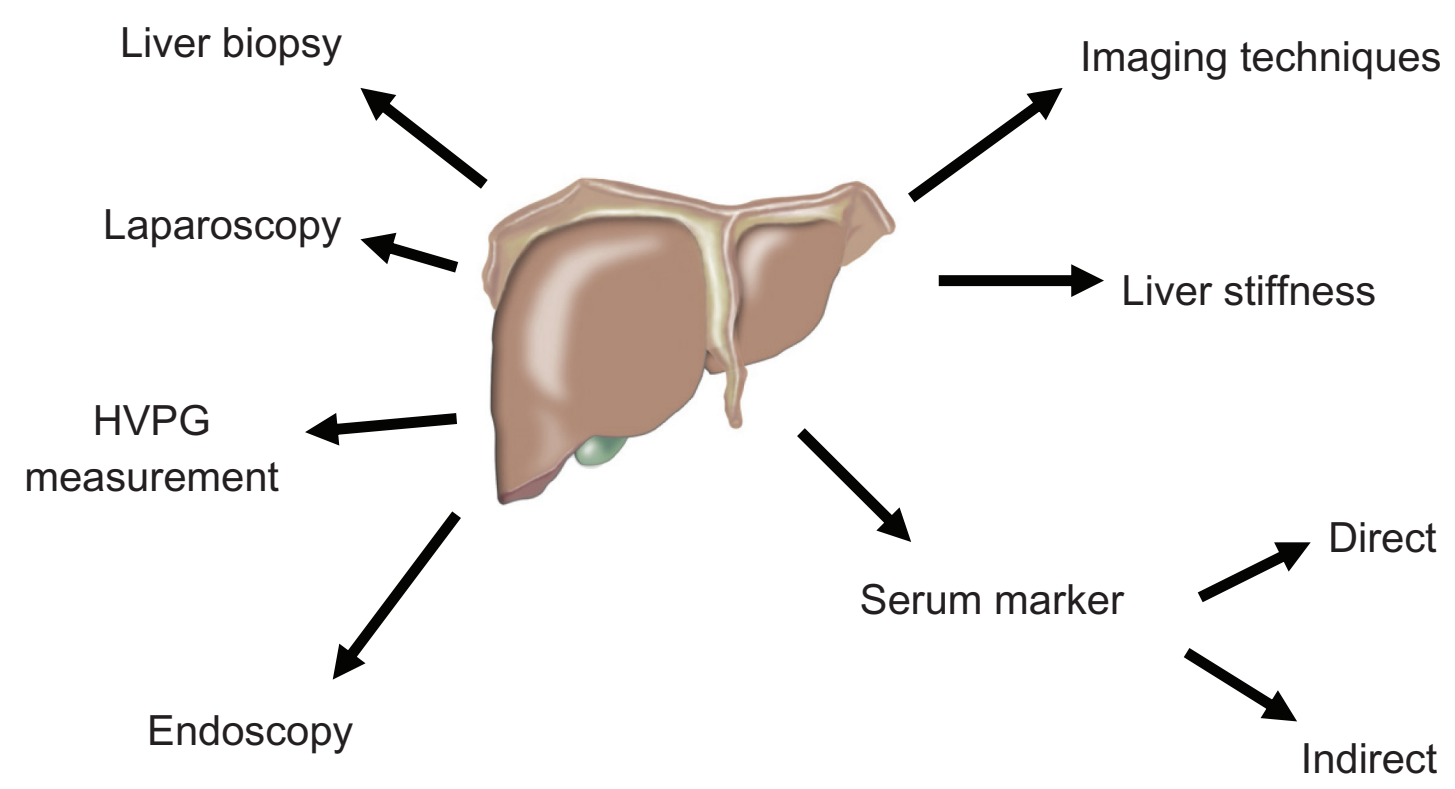

Figure I Invasive and noninvasive methods to determine liver fibrosis hepatic venous pressure gradient. 
better understand what stiffness means. From a physical and mechanical point of view, stiffness can be defined as the modulus of elasticity or Young's modulus (E). Hooke's law of elasticity is an approximation that states that the extension of a material is directly proportional to the applied stress, $\sigma=\mathrm{E} \varepsilon$, where $\sigma$ is the stress applied to the material, and $\varepsilon$ is the strain induced in the material. Stiffness $(\mathrm{E})$ is expressed in kilopascals $(\mathrm{kPa})$ and represents the resistance of material to deformation. While stiff materials, such as concrete, exhibit low strain even at high stress, soft materials such as biological soft tissues exhibit large strain even at low stress.

LS, like any other soft tissue stiffness, depends on many factors. The first and main factor is the extracellular matrix of the organ. The extracellular matrix is a deformable structure that transfers the external forces through the liver. It can be compared to the foundation of a building. A second factor is the constraints that are applied on the organ. The more pressure that is applied to the liver at its boundaries, the stiffer it gets. A third factor is the internal pressure inside the organ - if blood, or another liquid is coming in and out, then stiffness will depend on the resistance that the organ applies to the flow. A fourth and important factor is the viscous effects which influence the time constant over which stiffness is tested. This effect is linked to frequency, ie, stiffness depends on frequency. While liver is soft at very low frequency (on the order of several hertz) which corresponds to manual palpation time-constant, it tends to be much harder at high frequencies (over several tens of kilohertz).

\section{Measurement of liver stiffness using transient elastography (FibroScan ${ }^{\circledR}$ )}

The FibroScan $^{\circledR}$ (FS) (Echosens, Paris, France) device is the first elastography technique developed to quantitatively and noninvasively assess soft biological tissue stiffness in vivo. Liver was a natural first organ to study due to its size and rather homogenous texture. ${ }^{8}$ In principle, shear waves are generated through the liver and LS is deduced from their velocity. FS uses the technique called transient elastography (TE) or vibration-controlled transient elastography $\left(\mathrm{VCTE}^{\mathrm{TM}}\right)$. It is based on the controlled generation of a transient shear wave using a servo-controlled vibration of known frequency and amplitude. LS is computed from the velocity of these mechanical waves using the following equation:

$$
\mathrm{E}=3 \rho \mathrm{V}_{s}^{2}
$$

where $\mathrm{E}$ is the Young's modulus or stiffness, $\rho$ is the density, and $\mathrm{V}_{s}$ the shear velocity. The shear velocity measured by VCTE $^{\mathrm{TM}}$ is a group velocity around $50 \mathrm{~Hz}$. Minimum and maximum stiffness values that can be measured by FS are $1.5 \mathrm{kPa}$ and $75.0 \mathrm{kPa}$ respectively.

Technically, FS consists in a dedicated acquisition platform that includes a single channel ultrasound analog front end to emit and receive ultrasound signals, and a servocontrolled vibrator for the shear wave generation. The probe itself contains a sophisticated vibrator on the axis of which a single element ultrasound transducer is mounted. As shown in Figure 2, the vibration consists of a sinusoid period with a center frequency of $50 \mathrm{~Hz}$. Its amplitude depends on the probe model: $2 \mathrm{~mm}$ peak-to-peak (PP) with the standard probe (model M), $1 \mathrm{~mm}$ PP with the pediatric probe (model S), and $3 \mathrm{~mm}$ PP with the obese patients dedicated probe (model XL). The shear wave propagation is monitored using ultrafast ultrasound acquisitions.

In the standard examination procedures, LS measurements using FS are performed on the right lobe of the liver in intercostal position (see Figure 3). This prevents direct

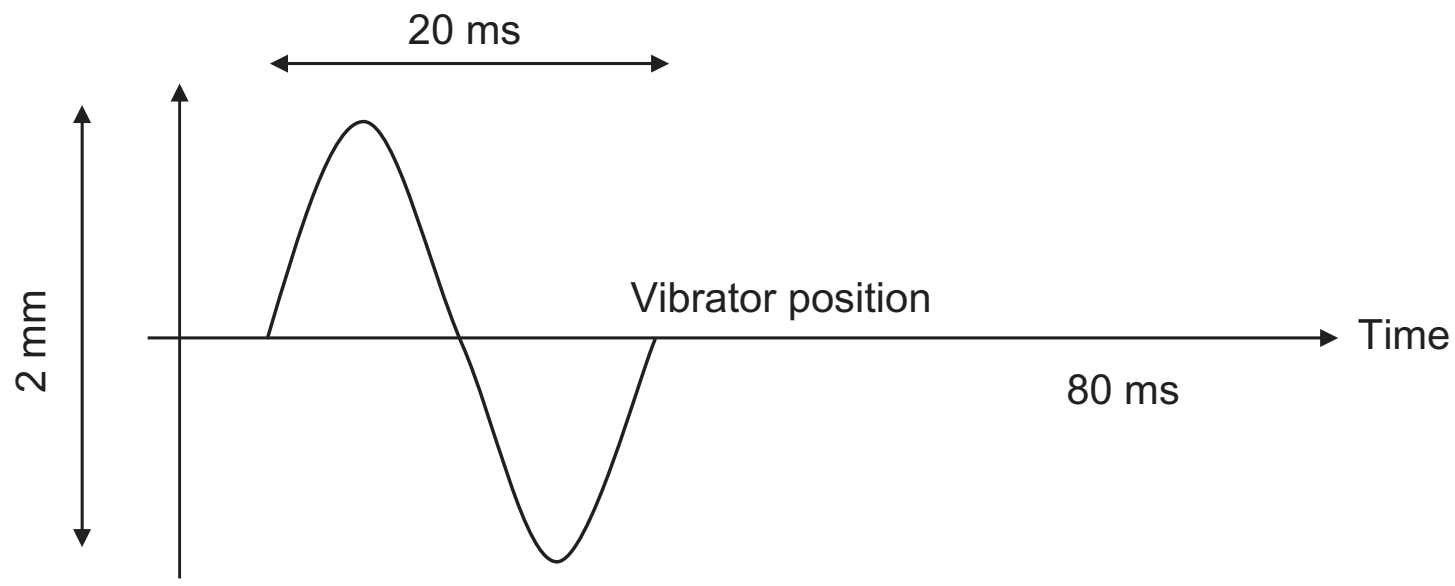

Figure 2 FibroScan ${ }^{\circledR}$ vibration consists of a period with a center frequency of $50 \mathrm{~Hz}$. The standard M probe has a 2 mm peak-to-peak amplitude. 


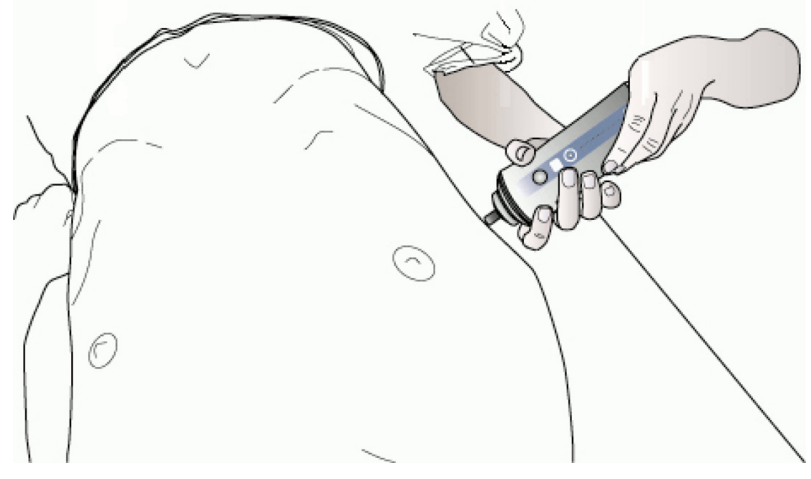

Figure 3 Liver stiffness measurements are performed on the right lobe of the liver in intercostal position using FibroScan ${ }^{\circledR}$.

compression of the liver that would eventually affect LS values. The patient is lying on his back with the right arm behind the head in order to enlarge intercostals space as much as possible. The operator uses ultrasound M-mode and A-mode images (Figures $4 \mathrm{~A}$ and $\mathrm{B}$ ) to locate the liver, and triggers the measurement by pushing on the probe button. The shear wave can be observed on the elastogram image (Figure 4C) which represents the strains induced in the liver as a function of time and depth. It is computed from ultrasound data acquired at a very high frame rate during the shear wave propagation which lasts $80 \mathrm{~ms}$.

\section{Measurement of liver stiffness using other elastographic techniques and normal stiffness values}

Although FS has been the first noninvasive elastographic techniques in practical use to assess LS, other competingtechnical approaches have been developed. They are under current cross-validation and it is still too preliminary for a final statement (see Table 1). Magnetic resonance elastography

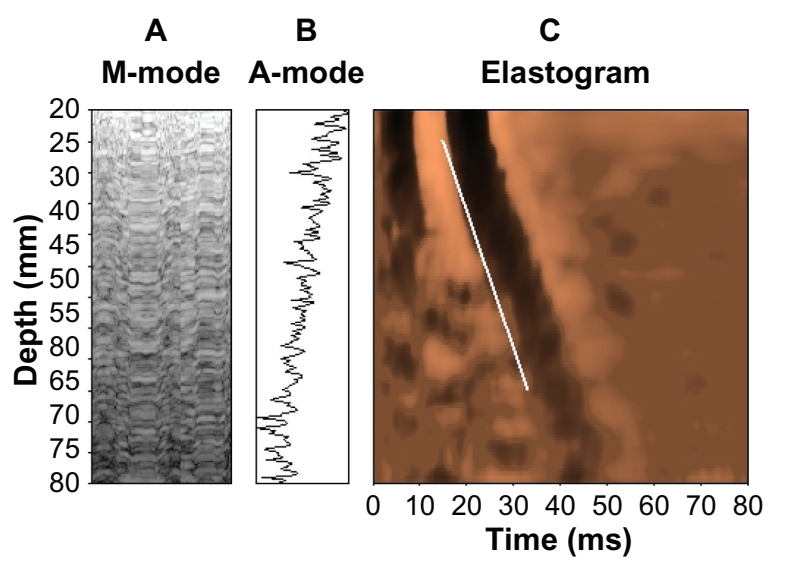

Figure 4 FibroScan ${ }^{\circledast}$ operator uses A) A-mode and B) M-mode images to locate the liver. The shear wave velocity is deduced from the $\mathbf{C}$ ) elastogram which represents the strains induced in the liver by the shear wave propagation as a function of time and depth.
(MRE) was introduced in 1995 by Muthupillai ${ }^{9}$ and is now commercially available as MR-Touch (General Electric). Rouviere et $\mathrm{al}^{10}$ measured liver shear stiffness in healthy volunteers and in patients with liver fibrosis. The shear stiffness $\mu$ can be deduced from Young's modulus E (as measured by FS) using the simple relationship: $\mu=E / 3$. Klatt et al measured the shear elastic modulus in 12 healthy volunteers and two patients. ${ }^{11}$ Results obtained on volunteers are close to $6 \mathrm{kPa}$ when converted in Young's modulus. MRE looks very promising. It seems to have a smaller standard deviation and, naturally, offers the combination of magnetic resonance imaging and elastography in one setting for different organs. However, it is an expensive, time consuming, certainly not a bedside procedure, and cannot be used in the setting of metal implants. FS has been directly cross-validated with MRE using artificial phantoms with an excellent correlation of $r=0.96 .{ }^{12,13} \mathrm{~A}$ linear correlation between LS and fibrosis stage has been observed in animal fibrosis models using MRE. ${ }^{14}$

In addition to FS, various ultrasound-scanner-compatible elastography procedures are currently being evaluated. FS should not be mismatched with conventional static elastography that is now integrated in many ultrasound devices. The first system based on static elastography was the real time elastography (HI-RTE). It allows a visualization of relative stiffness within a B-ultrasound image using a red and blue color map. However, HI-RTE does not allow the quantitative measurement of stiffness values and, hence, pilot studies did not show a satisfying correlation with fibrosis score as compared to FS. ${ }^{15}$

More recently, several techniques ${ }^{16-18}$ based on radiation force ${ }^{19}$ have been proposed for LS measurement. These techniques use high intensity ultrasound beams to induce displacements inside the liver remotely. Acoustic Radiation Force Impulse (ARFI) with Virtual Touch ${ }^{\mathrm{TM}}$ tissue quantification has been introduced by Siemens (German). First ARFI-based results have been presented at international meetings in cross-validation with FS. Reasonable areas under receiver operating characteristic curves (AUROCS) for F3-4 fibrosis $>0.86$ have been presented on various diseases with excellent interobserver variability of $0.98^{20,21}$ and a good correlation with FS of $r=0.65 .^{22}$ In contrast to FS, ascites does not impose a limitation to ARFI. However, up to now, FS seems to outscore the identification of F2-4 fibrosis stages with regards to diagnostic accuracy. ${ }^{21}$

Since the physiological determinants of LS are not completely understood and the detection methods vary considerably, it is still a debate how to define normal LS values. In a recent study, we could demonstrate that simple 
Table I Comparison of various techniques to assess liver stiffness

\begin{tabular}{|c|c|c|c|c|c|c|}
\hline & Method & $\begin{array}{l}\text { Product } \\
\text { name }\end{array}$ & $\begin{array}{l}\text { Vibration } \\
\text { mode/source }\end{array}$ & Frequency & Advantages & Limitations \\
\hline Static elastography & $\begin{array}{l}\text { Quasi-static } \\
\text { compression }\end{array}$ & eg, by Hitachi & None & Not applicable & $\begin{array}{l}\text { Widely available in } \\
\text { ultrasound scanners }\end{array}$ & Qualitative only \\
\hline $\begin{array}{l}\text { Magnetic resonance } \\
\text { elastography }\end{array}$ & Shear wave & $\begin{array}{l}\text { Optima } \\
\text { MR450 w I.5 T }\end{array}$ & $\begin{array}{l}\text { Continuous } \\
\text { mechanical } \\
\text { actuator }\end{array}$ & $50-60 \mathrm{~Hz}$ & $\begin{array}{l}\text { 2D/3D stiffness } \\
\text { mapping, frequency } \\
\text { controlled vibration, } \\
\text { other organs }\end{array}$ & $\begin{array}{l}\text { Expensive, metal } \\
\text { implants (pace makers, } \\
\text { bone implants) }\end{array}$ \\
\hline $\begin{array}{l}\text { Acoustic radiation } \\
\text { force impulse }\end{array}$ & Shear wave & $\begin{array}{l}\text { Acuson } \\
\text { S2000 }\end{array}$ & $\begin{array}{l}\text { Transient } \\
\text { radiation } \\
\text { force }\end{array}$ & & Ascites, other organs & $\begin{array}{l}\text { Accuracy, limited } \\
\text { clinical data }\end{array}$ \\
\hline $\begin{array}{l}\text { Vibration-controlled } \\
\text { transient elastography }\end{array}$ & Shear wave & FibroScan ${ }^{\circledR}$ & $\begin{array}{l}\text { Transient } \\
\text { mechanical } \\
\text { actuator }\end{array}$ & $50 \mathrm{~Hz}$ & $\begin{array}{l}\text { Largely validated, } \\
\text { frequency controlled } \\
\text { vibration }\end{array}$ & $\begin{array}{l}\text { Sensitive to body } \\
\text { habitus (obesity, ascites, } \\
\text { bowel interpolate) }\end{array}$ \\
\hline
\end{tabular}

breath maneuvers such as valsalva, or position changes such as laying to standing position, can dramatically either permanently or temporarily increase LS up to the upper detection limit of $75 \mathrm{kPa} .{ }^{23}$ This study could also demonstrate that a horizontal position with normal breathing yields the lowest and most reproducible LS values. According to our experience, LS of $<6 \mathrm{kPa}$ can be considered as normal. ${ }^{23}$ Confirmation has come from a large screening study obtained on 1067 blood donors median with a medium LS of $4.4 \mathrm{kPa}(95$ th centile 6.7$) .{ }^{24}$ Tables 1 and 2 give an overview of recently reported stiffness values for liver and other organs obtained with different techniques for normal and pathological conditions.

\section{Liver stiffness assessment by FibroScan ${ }^{\circledR}$ - practical experience}

The major success of FS in measuring LS can be mainly explained by its true bedside test character that can be performed within 5-10 minutes. After a rapid training, FS provides a reasonable performance for the diagnosis of cirrhosis that is not influenced substantially by any other feature. ${ }^{25} \mathrm{FS}$ has an excellent interobserver rate especially without elevated transaminase ${ }^{26}$ and a fast learning curve. ${ }^{27}$ In addition, no significant difference in LS values have been found whether they were obtained from the fifth, sixth and seventh intercostal space. ${ }^{28}$ Thus, in general, FS measurements can be routinely performed in more than $95 \%$ of patients. Major limitations are severe obesity and ascites that directly weaken the ultrasound signal. ${ }^{29}$ In some collectives such as patients with decompensated cardiac insufficiency, the successful performance of FS can drop down to ca. 50\%. ${ }^{30}$ However, with the development of the novel XL probe, these obstacles could be drastically overcome. In our own preliminary experience, we found that the XL probe could measure LS in $70 \%$ of patients where the normal $\mathrm{M}$ probe were not applicable. Moreover, the XL probe could not only be successfully applied to severely obese patients but also to patients with ascites and lean patients with an ultrasounddiffracting subcutaneous fat tissue. It will be interesting to learn in the future why some nonobese people are critical to be measured by FS.

\section{Potential artificial results obtained by FibroScan ${ }^{\circledR}$}

Shear wave propagation in soft biological tissues might be very complex. Thus, LS is calculated as the median of 5 to 10 valid measurements. Outliers are removed and the interquartile range is provided as a mean to check for the quality of the measure. Furthermore, FS implements special algorithms to automatically reject incorrect measurements which are ranked invalid and are thus not included in stiffness calculation. However some cautions must be taken, especially with probe perpendicularity and rib cage intercostal spaces.

Table 2 Stiffness and shear velocity of liver and other organs by various methodological approaches

\begin{tabular}{lllll}
\hline & Liver & Pancreas & Spleen & Kef. \\
\hline MRE & & & \\
ARFI & $\sim 2.2 \mathrm{kPa}(60 \mathrm{~Hz})$ & $\sim 2.0 \mathrm{kPa}(60 \mathrm{~Hz})$ & $2.44 \mathrm{~m} / \mathrm{s}$ & $2.3 \mathrm{kPa}(90 \mathrm{~Hz})$ \\
VCTE/FS & $1.16-1.59 \mathrm{~m} / \mathrm{s}$ & $1.4 \mathrm{~m} / \mathrm{s}$ & $2.24 \mathrm{~m} / \mathrm{s}$ & $108,46,20,109$ \\
\hline
\end{tabular}

Note: "Young's modulus E (as measured by VCTE/FS) is three times higher than the MRE-measured shear stiffness $\mu$ according to the following equation: $\mu=E / 3$. Abbreviations: MRE, magnetic resonance elastography; ARFI, acoustic radiation force impulse; VCTE, vibration-controlled transient elastography ${ }^{\mathrm{TM}}$; FS, FibroScan ${ }^{\circledR}$. 
First, it is important that the probe is placed perpendicular to the skin surface when measuring LS to prevent overestimation which could happen if the shear wave propagation is misaligned with the ultrasound beam. Second, the probe model should be adapted to the patient morphology so that the ribs do not contribute to the shear wave generation. This would affect the measurement quality by inducing secondary shear waves. Although diffraction effects by ribs are rare, they may lead to confusion and misinterpretation.

Interestingly, shear waves do not propagate through liquids because they are elastic waves and only pressure waves can propagate through liquids such as those which are used by ARFI. For this reason patients with ascites may not be measurable with FS as far as no physical contact exists between the liver and the intercostals wall.

\section{(Patho)physiology of liver stiffness Liver stiffness as surrogate marker of fibrosis stage}

LS has mainly been studied in patients with viral hepatitis $\mathrm{B}$ and C (HBV and HCV), ${ }^{8,25,31-37}$ and to a lesser extent in alcoholic liver disease (ALD) $)^{38-40}$ and primary biliary cirrhosis (PBC)/primary sclerosing cholangitis (PSC). ${ }^{41-43}$ In contrast, only random and preliminary reports exist on autoimmune hepatitis $^{44,45}$ and nonalcoholic liver disease (NALD). ${ }^{46,47}$ Table 3 shows the performance of LS to assess fibrosis stages F3 and F4 for various diseases (selected studies). Table 4 compares normal and fibrotic stiffness values obtained by different methods. The major experience of these studies can be summarized as follows:

a. LS correlates well with fibrosis stage typically with an $\mathrm{r}>0.7$ and $P<0.005$.

b. Advanced fibrosis stage F3 and cirrhosis (F4) are identified via LS with high accuracy (AUROC >0.9).
This is mainly due to the so called bridging fibrosis (the continuous formation of collagen septa between liver lobuli) that are characteristic for these fibrosis stages. In contrast, fibrosis stages F1 and F2 only mildly increase LS. Therefore, these fibrosis stages are not well discriminated via the measurement of LS.

c. Cut-off values have been defined that allow the diagnosis of advanced fibrosis (F3/F4). Despite some variability, cut-off values of 8.0 and $12.5 \mathrm{kPa}$ are widely accepted to identify patients with F3 and F4 fibrosis, respectively (Figure 5).

It has also become rapidly clear that cut-off values differ between various chronic liver diseases, being tentatively higher in disease with pronounced inflammation or cholestasis such as ALD, PSC or PBC. This is one reason to ask for studies with well defined and homogenous patient populations. Potential causes for varying cut-off values will be discussed below.

\section{Fibrosis assessment by liver stiffness and comparison with other noninvasive fibrosis markers/techniques}

\section{Imaging techniques}

Since abdominal ultrasound is routinely and rapidly performed in liver patients, a few studies have naturally asked the questions whether LS provides additional information with regard to fibrosis. In comparison to FS, ultrasound is a subjective examination that largely depends upon the experience of the examiner. It is not always clear that only a few ultrasound signs such as nodular aspects of the liver surface, or vascular collaterals are so called sure ultrasound signs of liver cirrhosis (but not splenomegaly or ascites). In an actual larger study on 320 patients with various liver disease, the diagnostic accuracy of LS was significantly superior to ultrasound. ${ }^{48}$ In our own experience, FS recognized generally more than twice

Table 3 Liver stiffness and fibrosis stages in various liver diseases

\begin{tabular}{|c|c|c|c|c|c|c|c|}
\hline Disease & $\mathbf{N}$ & $\begin{array}{l}\text { Fibrosis-LS } \\
\text { correlation }\end{array}$ & $\begin{array}{l}\text { AUROC } \\
\text { F3 }\end{array}$ & $\begin{array}{l}\text { AUROC } \\
\text { F4 }\end{array}$ & $\begin{array}{l}\text { Cut-off } \\
\text { F3 }\end{array}$ & $\begin{array}{l}\text { Cut-off } \\
\text { F4 }\end{array}$ & Ref. \\
\hline $\mathrm{HCV}$ & 193 & & 0.9 & 0.95 & 9.5 & 12.5 & 32 \\
\hline $\mathrm{HCV}$ & 935 & & 0.89 & 0.91 & & & 25 \\
\hline HCV/HIV & 72 & $0.48 ; P<0.0001$ & 0.91 & 0.97 & & 11.9 & 37 \\
\hline HBV & 202 & $0.65 ; P<0.001$ & 0.93 & 0.93 & & 11.0 & 110 \\
\hline ALD & 103 & $0.72, P<0.014$ & 0.9 & 0.92 & 11 & 19.5 & 38 \\
\hline ALD & 45 & & & 0.97 & & 25.8 & 39 \\
\hline ALD & 101 & $0.72 ; P<0.00 I$ & 0.91 & 0.92 & 8 & 11.5 & 40 \\
\hline NAFLD & 246 & & 0.92 & 0.95 & 7.9 & & 47 \\
\hline $\mathrm{PBC} / \mathrm{PSC}$ & 101 & $0.84, P<0.0001$ & 0.95 & 0.96 & 9.8 & 17.3 & 42 \\
\hline $\mathrm{PBC}$ & 80 & & & 0.96 & & & 43 \\
\hline
\end{tabular}

Abbreviations: $\mathrm{HCV}$, hepatitis $\mathrm{C}$ virus; HIV, human immunodeficiency virus; HBV, hepatitis B virus; ALD, alcoholic liver disease; NAFLD, nonalcoholic fatty liver disease; LS, liver stiffness; PBC, primary biliary cirrhosis; PSC, primary sclerosing cholangitis; AUROC, areas under receiver operating characteristic curves. 
Table 4 Comparison of liver stiffness obtained by various techniques for normal and cirrhotic livers

\begin{tabular}{lllll}
\hline & Normal & $\begin{array}{l}\text { Fibrosis } \\
(\text { F3 })\end{array}$ & $\begin{array}{l}\text { Cirrhosis } \\
(\text { F4) }\end{array}$ & Ref. \\
\hline MRE $^{*}$ & $2 \mathrm{kPa}$ & & $5 \mathrm{kPa}$ & 10 \\
& $(90 \mathrm{~Hz})$ & & $(90 \mathrm{~Hz})$ & \\
ARFI & $1.5 \mathrm{~m} / \mathrm{s}$ & $1.8 \mathrm{~m} / \mathrm{s}$ & $>1.95 \mathrm{~m} / \mathrm{s}$ & 111 \\
& & & $2.1-2.3 \mathrm{~m} / \mathrm{s}$ & 20,109 \\
VCTE/FS & $2-6 \mathrm{kPa}$ & $>8 \mathrm{kPa}$ & $>12.5 \mathrm{kPa}$ & see above ${ }^{23}$ \\
& $(50 \mathrm{~Hz})$ & $(50 \mathrm{~Hz})$ & $(50 \mathrm{~Hz})$ & \\
\hline
\end{tabular}

Note: "Young's modulus E (as measured by FibroScan/VCTE/FS) is three times higher than the MRE-measured shear stiffness $\mu$ according to the following equation: $\mu=E / 3$. Abbreviations: MRE, magnetic resonance elastography; ARFI, acoustic radiation force impulse; VCTE, vibration-controlled transient elastography ${ }^{\mathrm{TM}}$; FS, FibroScan ${ }^{\circledR}$.

of patients with F3/4 fibrosis compared to ultrasound. ${ }^{49}$ This means in numbers, that more than 20 patients with $\mathrm{F} 3 / 4$ fibrosis were not recognized by routine ultrasound, while FS identified almost all 45 patients. It should be pointed out that these are results for a typical clinical routine ultrasound performed within 15-20 min; the accuracy of ultrasound can certainly be increased by a more meticulous and time consuming procedure. However, the time-intensive ultrasound is still subjective and can typically not be performed during the daily practice in most regular hospitals and outpatient departments. Therefore, as a rule of thumb, the rapid 5-10 min FS recognizes ca. twice as many patients with advanced fibrosis as compared to the routine ultrasound.

\section{Serum markers}

Although serum markers that are used within scores such as the Fibrotest, APRI score, etc, are widely explored and have been also cross-validated with FS, ${ }^{22,35,50-54}$ the authors, up to now, do not generally recommend their use and FS seems to outscore all of these tests. However, we admit, as will be discussed below, that a combination and a refined algorithm using elastography, serum markers, and imaging techniques may optimize a cost-efficient screening for liver fibrosis in certain settings or spare patients from invasive histology. ${ }^{55}$ The major problem is that serum markers reflect the profibrogenic or profibrolytic activity, but do not yield any information about the net deposition of matrix in the liver which are not necessarily correlated to each other.

\section{Other factors that increase liver stiffness}

It has been rapidly learnt that LS is also increased by other confounding factors such as hepatitis, mechanic cholestasis, liver congestion, cellular infiltrations, and deposition of amyloid irrespective of fibrosis stage (see Figures 5 and 6 ). These important interferences will now be discussed in more detail. It should be mentioned that steatosis does not increase $\mathrm{LS}^{40,56}$ although it is often regarded as an essential initial state in chronic liver disease. Rather, steatosis may slightly decrease LS.

\section{Inflammation (hepatitis)}

LS can be dramatically increased during laboratory signs of hepatitis ${ }^{50,57,58}$ independent of the degree of fibrosis. These conditions may increase LS to a degree that would otherwise suggest advanced liver cirrhosis (ie, stiffness values of $12.5 \mathrm{kPa}$ and above). In our recent studies on patients with

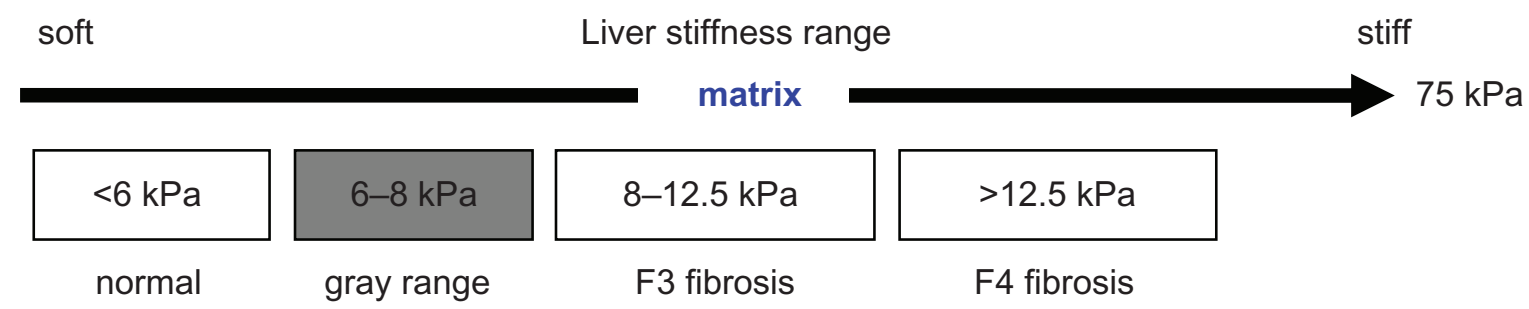

Pressure (reversible) $\quad \max$

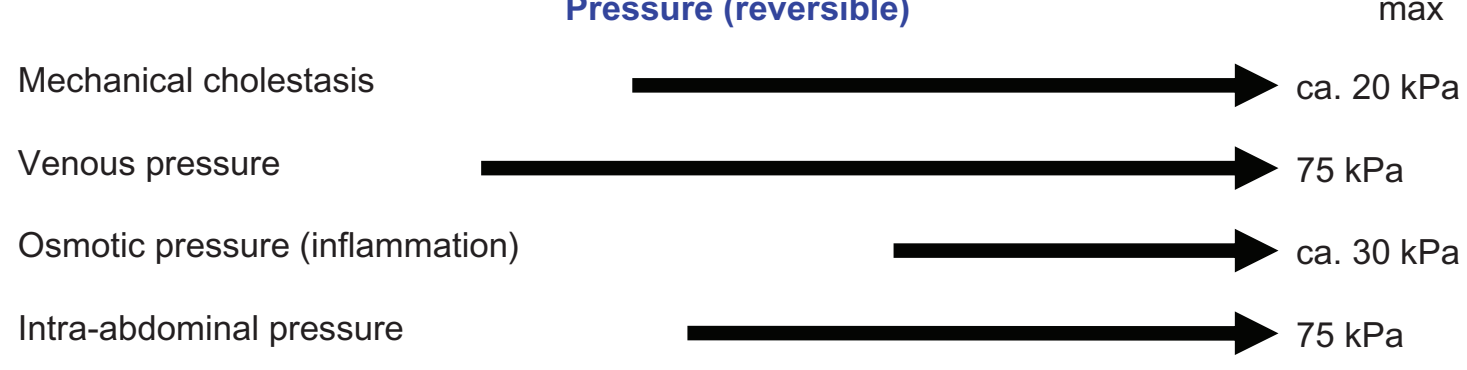

Figure 5 Liver stiffness range caused by matrix deposition (fibrosis) and pressure changes (osmotic, hydrostatic, intra-abdominal). 


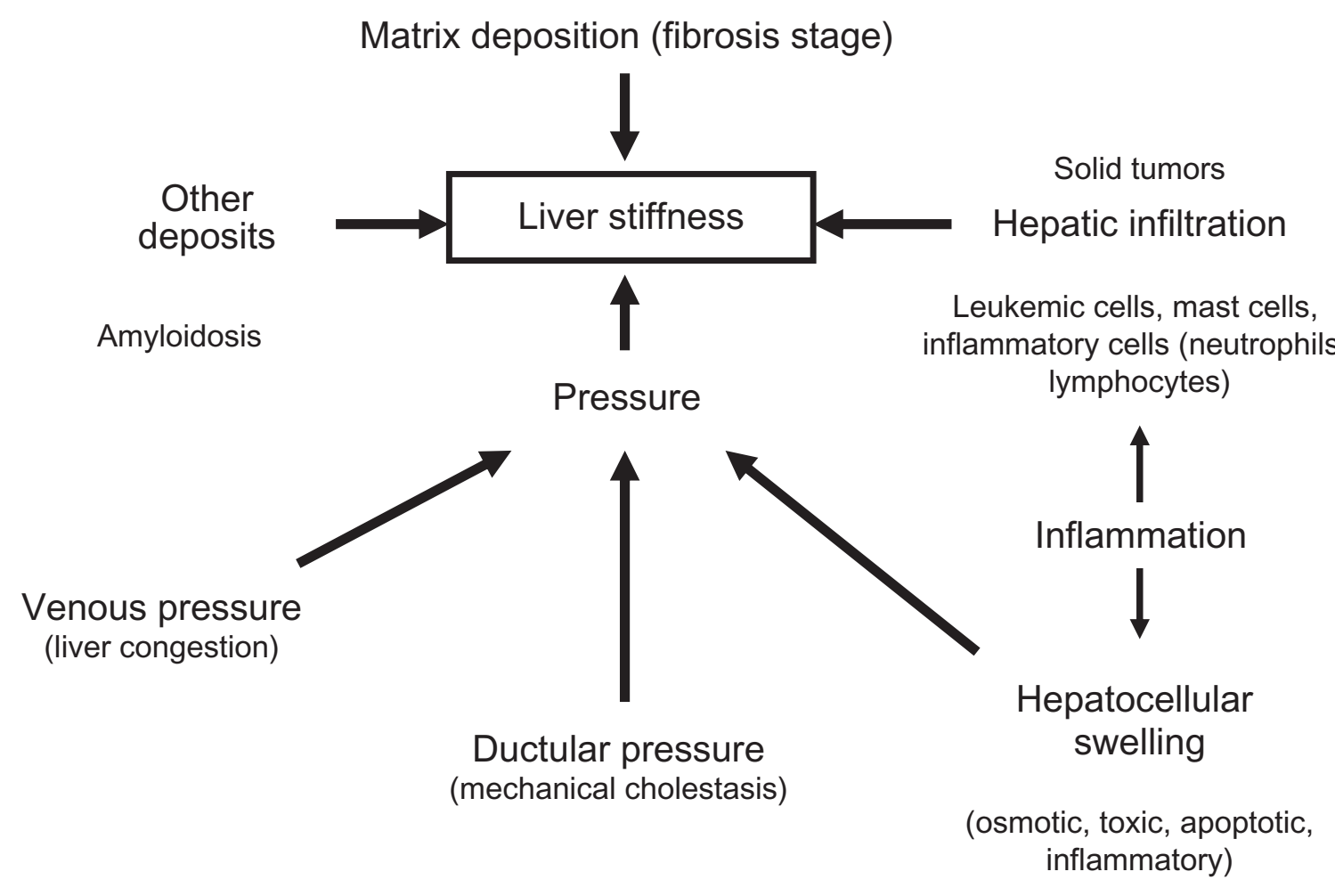

Figure 6 Not only matrix but also pressure-associated conditions influence liver stiffness.

ALD undergoing alcohol detoxification, LS was initially increased up to $50 \mathrm{kPa}$ but could decrease within 1 week by $30 \mathrm{kPa} .{ }^{40} \mathrm{In} \mathrm{HCV}$ patients with biochemical remission (either spontaneous or after antiviral therapy), LS was lower than in patients with identical fibrosis stage, but elevated alanine transaminase (ALT). The LS dynamic profiles paralleled those of ALT, increasing 1.3- to 3-fold during ALT flares in patients with hepatitis exacerbations. ${ }^{50}$ In patients with HBV infection, fibrosis assessment was unreliable if serum transaminases were higher than twice of normal values. ${ }^{59} \mathrm{In}$ our experience, ongoing biochemical activity of liver disease in form of increased transaminases leads to an overestimation of fibrosis stage, since hepatitis per se increases LS, irrespective of fibrosis. What are the underlying factors leading to increased LS in these patients? In our sequential FS study on 50 patients with ALD undergoing alcohol detoxification we could show the following phenomena: ${ }^{40}$

a. All transaminase levels decreased during alcohol detoxification, and almost all LS values decreased during the observation interval.

b. The higher the decrease in transaminases was, the higher was the decrease of LS.

c. Excluding patients with significant ongoing biochemical activity of hepatitis from fibrosis assessment by FS significantly improved AUROC for F3/4 fibrosis. d. Additional histological information on inflammation did not further improve the diagnostic accuracy.

This study thus shows that, at least in patients with ALD, serum transaminases truly reflect the degree of hepatitis and that the inflammation is a critical factor determining LS. In our patient population, the decrease of aspartate aminotransferase (AST) correlated better with the decrease of LS as compared to ALT. It is interesting to learn that in HCV infected patients similar observations have been made. Here, AST was found to be the unique variable significantly related $(P=0.046)$ with discordance between biopsy and LS. ${ }^{60}$ Subanalysis of histological scores with LS values was also very revealing. Here, necrosis, hepatocyte swelling and the degree of inflammation correlated with LS but not steatosis. This has been partly confirmed in a recent study on patients with nonalcoholic fatty liver disease (NAFLD) ${ }^{47}$ We conclude from our study that patients with an AST $>100 \mathrm{U} / \mathrm{L}$ lead to an overestimation of fibrosis stage. These patients should be first detoxified from alcohol and LS should be obtained after normalization. A refined algorithm will be discussed below.

\section{Cholestasis}

In a recent study on 15 patients with mechanic cholestasis due to tumor obstruction (pancreas carcinoma, Klatskin 
tumor, liver metastases, and gastrointestinal stromal tumor [GIST]) or choledocholithiasis, we could demonstrate that mechanical cholestasis per se can drastically and reversibly increase LS. ${ }^{61}$ LS correlated significantly with a decrease in bilirubin, but not with gamma-glutamyl transpeptidase (GGT), alkaline phosphatase (AP), AST, or ALT. We further confirmed the direct relation between LS and choletasis in bile duct ligation experiments on landrace pigs. The bile duct ligation over $120 \mathrm{~min}$ led to a significant swelling of the liver and a tightly palpable gall bladder. LS values doubled during bile duct ligation and reached values suggesting F3 fibrosis. After removal of the bile duct ligation and a recovery period of $30 \mathrm{~min}$, LS values returned to almost normal values around $6.1 \mathrm{kPa}$. The reasons underlying the high stiffness in cholestasis are unknown but could be related to tissue swelling, edema and increased intracellular pressure due to impaired bile flow. In addition, cholestasis might be a general phenomenon leading to increased LS in various chronic liver diseases as intrahepatic cholestasis has been shown to correlate strongly with LS in patients with acute hepatitis $^{58}$ but also ALD. ${ }^{40}$

\section{Liver congestion and venous pressure}

Random observation had suggested earlier that FS is unreliable in patients with liver congestion, for example due to cardiac insufficiency. We could recently demonstrate that the central venous pressure directly controls LS in a reversible manner. ${ }^{30}$ Over a wide range, LS is a linear function of intravenous pressure reaching the upper detection limit of $75 \mathrm{kPa}$ at an intravenous pressure of $36 \mathrm{~cm}$ water column. We eventually showed in 10 patients with decompensated congestive heart failure that LS is dramatically elevated under such pathological conditions and rapidly decreases during clinical recompensation due to diuretic therapy. Since fibrosis state cannot change within such a short period of time, these findings further underline the direct dependence of LS on venous pressure. The majority of patients with decompensated cardiac failure had initial LS far above the cut-off value of $12.5 \mathrm{kPa}$ which is generally accepted for the diagnosis of F4 fibrosis, reaching up to $51.3 \mathrm{kPa}$. Although LS decreased in all patients during therapy with diuretics it only fell below $12.5 \mathrm{kPa}$ in two of them while seven remained in the range of $\mathrm{F} 4$ fibrosis. Older age as a reason for increased LS can be excluded as a recent study by Sirli and colleagues showed. ${ }^{62}$ Thus, increased LS could be due to the onset of cardiac fibrosis in these cases, and fibrosis assessment by FS will be especially challenging in patients with cardiac insufficiency since both fibrosis and venous pressure increase LS. It also remains questionable in this context whether recently reported increased LS in patients with failing Fontan circulation was indeed due to cardiac liver fibrosis, ${ }^{63}$ or just elevated central venous pressure since no sequential LS measurements were performed. On a special note, LS may become a useful noninvasive tool for screening cardiac patients and identifying those that are at risk of cardiac cirrhosis since increased venous pressure (but not abnormal liver function tests) has been recognized as major risk factor of cardiac fibrosis. ${ }^{64}$

\section{Liver infiltration, deposits, rare diseases}

It is a daily experience of surgeons that hepatic tumor infiltration increases LS. Therefore, focal or nodular masses within the liver should be excluded by ultrasound prior to FS However, since not all hepatic masses can be detected by ultrasound, one should be aware of such potential misinterpretations of LS measurements. A typical finding during LS measurements in, for example, a metastatic liver, are extremely variable stiffness values that clearly depend on position changing of the probe. ${ }^{61}$

However, also rare and less visible infiltration with mast cells can also lead to dramatically increased $\mathrm{LS}^{23}$ We recently reported on a patient with systemic mastocytosis showing an LS of $75 \mathrm{kPa}$ (upper detection limit). The patient had otherwise suspicious signs of liver cirrhosis (splenomegaly, ascites, varices). However, liver synthesis was normal and the differential blood count showed an increased number of mast cells. Diagnosis was ultimately confirmed by liver biopsy. An important noncancerous differential diagnosis of increased LS is amyloidosis. Increased LS due to amyloid deposits has been demonstrated in animal models (submitted by Sandrin L, et al) and humans with amyloidosis A. ${ }^{65,66}$ Interestingly, all these clinical entities showed pronounced hepatomegaly.

\section{Liver stiffness and clinical end points}

The ultimate goal of novel medical techniques should be to improve diagnosis or therapy of human disease. Therefore, with regard to LS, we would like to see whether it improves the early recognition of cirrhosis-related complications such as portal hypertension, esophageal varices, primary liver cancer or the response to therapies.

\section{Liver stiffness and portal hypertension}

Since fibrosis increases the hepatic vascular resistance and ultimately leads to portal hypertension (see Figure 7), it 


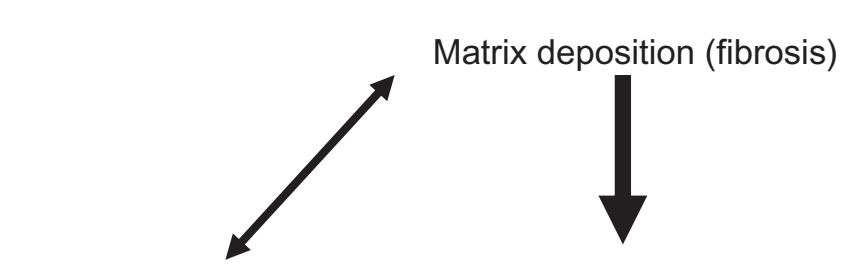

Liver stiffness

Vascular resistance
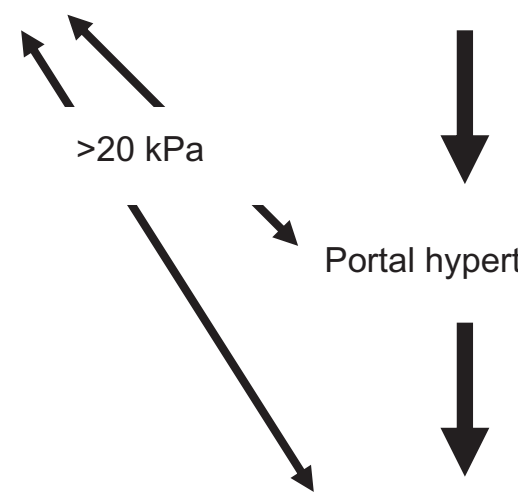

Portal hypertension

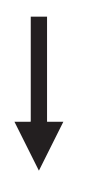

Esophageal varices

Figure 7 Relation of liver stiffness with clinical fibrosis-related entities such as fibrosis stage, portal hypertension and esophageal bleeding.

was just a matter of time to test whether LS could be used as a diagnostic test for portal hypertensions. Meanwhile, several studies have compared LS directly against invasive hepatic venous pressure gradient (HVPG) or the presence of esophageal varices in adults $(0.84-0.86)^{54,67-73}$ and children. ${ }^{70}$ As shown in Table 5, there is an excellent direct correlation between LS and HVPG $(0.84-0.86)^{67-69}$ with an AUROC for detection of significant HVPG $(>6-12 \mathrm{~mm} \mathrm{Hg})$ of 0.92-0.99. ${ }^{67-69}$ A cut-off value of ca. $20 \mathrm{kPa}(13.6-34.9 \mathrm{kPa})$ predicted significant HVPG. ${ }^{67-69}$ Interestingly, lower values were found for HCV (ca. $20 \mathrm{kPa}$ ) as compared to ALD (34 $\mathrm{kPa}$ ). More interestingly, LS correlated with the degree of esophageal varices $(\mathrm{r}=0.6, P<0.0001)^{71}$ and the AUROC for the prediction of significant varices was $0.71-0.95$ with a comparable cut-off of ca. $20 \mathrm{kPa}$ (see Table 6). ${ }^{54,69-73}$

Figure 8 and Table 7 explain the more complex relation of liver and spleen stiffness with regard to the location of a potential thrombosis in the porto-caval system. This might explain why additional assessment of spleen stiffness could be better to predict portal hypertension and varices. ${ }^{74}$ In addition, cirrhosis develops in post or sinusoidal thrombosis, ${ }^{75,76}$ but not in presinosoidal idiopathic portal hypertension (IPH). ${ }^{77}$ Hence, no increased LS can be detected in patients with IPH and this explains why in some patients a normal LS does not exclude portal hypertension and the presence of varices. Indeed, a recent report documented five patients presented with variceal bleeding, two with splenomegaly, and one with ascites. All had large esophageal varices. Median HVPG was $8 \mathrm{~mm} \mathrm{Hg}$ (range 3.5-14.5), clearly underestimating the true portal pressure due to the presinusoidal component of portal hypertension. Median LS was $8.9 \mathrm{kPa}$ (range 6.8-14.9) and was unreliable in predicting the presence of fibrosis or of esophageal varices. ${ }^{77}$

\section{Liver stiffness and disease follow up Follow up studies in viral hepatitis $C$ patients}

Meanwhile, several longitudinal studies have been reported on LS during HCV treatment. Vergniol et al studied 416 patients, of whom 112 started treatment after enrolment. In multivariate analysis, treatment was the only factor independently associated with a fall in LS. ${ }^{78}$ Ogawa et al prospectively studied 145 Japanese patients with chronic $\mathrm{HCV}$ infection at baseline, at the end of treatment, and at 48 and 96 weeks after the end of treatment. LS significantly decreased in the groups with sustained virological response and biochemical response but not in the nonresponders. ${ }^{79}$ Andersen et al prospectively studied 114 Japanese patients with chronic HCV median follow up 47-48 months. In this study, LS was significantly lower for patients with sustained viral response (SVR). The differences were more pronounced in the F2-F4 fibrosis group. ${ }^{80}$

\section{Liver stiffness and alcoholic liver disease follow up}

We recently performed a sequential FS study in patients with ALD undergoing alcohol detoxicification ${ }^{40}$ to test if inflammation also interferes with LS assessment in ALD, and to provide a clinical algorithm for reliable fibrosis assessment in ALD by FS. We first performed sequential LS analysis before and after normalization of serum transaminases in a learning cohort of 50 patients with ALD admitted for alcohol detoxification. LS decreased in almost all patients within a mean observation interval of $5.3 \mathrm{~d}$. Six patients (12\%) would have been misdiagnosed with F3 and F4 fibrosis but LS decreased below critical cut-off values of 8 and $12.5 \mathrm{kPa}$ after normalization of transaminases. Of the serum transaminases, the decrease in LS correlated best with the decrease in glutamic oxaloacetic transaminase (GOT). No significant changes in LS were observed below GOT levels of $100 \mathrm{U} / \mathrm{L}$. After establishing the association between LS and GOT levels, we applied the rule of GOT $<100 \mathrm{U} / \mathrm{L}$ for reliable LS assessment in a second validation cohort of 101 patients with histologically confirmed ALD. By excluding those patients with GOT $>100 \mathrm{U} / \mathrm{L}$ at the time 
Table 5 Liver stiffness and hepatic venous pressure gradient

\begin{tabular}{|c|c|c|c|c|c|c|}
\hline Patients & $\mathbf{N}$ & $\begin{array}{l}\text { HVPG vs LS } \\
\text { correlation }\end{array}$ & $\begin{array}{l}\text { HVPG } \\
(\mathrm{mm} \mathrm{Hg})\end{array}$ & $\begin{array}{l}\text { AUROC for } \\
\text { significant portal } \\
\text { hypertension }\end{array}$ & $\begin{array}{l}\text { Cut-off for } \\
\text { significant portal } \\
\text { hypertension }\end{array}$ & Ref. \\
\hline $\mathrm{HCV}$ & 150 & $0.858 ; P<0.001$ & & 0.945 & $21 \mathrm{kPa}$ & 112 \\
\hline HCV, ALD & 92 & 0.76 & & & $\begin{array}{l}20.5 \mathrm{kPa}(\mathrm{HCV}) \\
34.9 \mathrm{kPa} \text { (ALD) }\end{array}$ & 68 \\
\hline $\begin{array}{l}\text { Liver } \\
\text { transplant } \\
\text { patients }\end{array}$ & 124 & $0.84 ; P<0.00 I$ & $>6$ & 0.93 & & 67 \\
\hline $\mathrm{HCV}$ & 61 & $0.8 \mathrm{I}, P<0.000 \mathrm{I}$ & $\begin{array}{l}>10 \\
>12\end{array}$ & $\begin{array}{l}0.99 \\
0.92\end{array}$ & $\begin{array}{l}13.6 \mathrm{kPa} \\
17.6 \mathrm{kPa}\end{array}$ & 69 \\
\hline
\end{tabular}

Abbreviations: HCV, hepatitis C virus; ALD, alcoholic liver disease; HVPG, hepatic venous pressure gradient; LS, liver stiffness; AUROC, areas under receiver operating characteristic curves.

of LS assessment from this cohort, the AUROC for cirrhosis detection by FS improved from 0.921 to 0.945 while specificity increased from 80 to $90 \%$ at a sensitivity of $96 \%$. A similar AUROC could be obtained for lower F3 fibrosis stage if LS measurements were restricted to patients with GOT $<50 \mathrm{U} / \mathrm{L}$. Histological grading of inflammation did not further improve the diagnostic accuracy of LS. In conclusion, coexisting steatohepatitis markedly increases LS in patients with ALD, independent of fibrosis stage. Postponing cirrhosis assessment by FS during alcohol withdrawal until GOT decreases to $<100 \mathrm{U} / \mathrm{mL}$ significantly improves the diagnostic accuracy.

\section{Liver stiffness and hepatocellular carcinoma}

Some studies have tested whether LS allows the prediction of $\mathrm{HCC}$ risk since cirrhosis is an independent risk factor of HCC. Foucher et al reported a cut off values for the presence of HCC of 53.7. ${ }^{81}$ Several studies have now looked in more detail into the relation of HCC and LS..$^{54,72,73,82-84}$ As can be seen from Table 8 , an LS of $>20 \mathrm{kPa}$ drastically increases the risk for HCC. Not by coincidence, this cut-off value is almost identical with the cut-of value for esophageal varices and significant portal hypertension.

\section{Liver stiffness and surgery}

\section{Liver stiffness and liver transplant}

Risk stratification of patients on the liver transplant waiting list is still an unresolved challenge, but the limited organ supply asks for more quantitative risk assessment strategies. LS could be a supplemental quantitative method since it recognizes pathological states of the liver that could all worsen the outcome such as fibrosis, inflammation, venous pressure, cholestasis, or portal hypertension. In a post-transplant study on patients infected with HCV, median LS at months 6, 9, and 12 were significantly higher in rapid fibrosers as compared to slow fibrosers. The slope of LS progression in rapid fibrosers was significantly greater than in slow fibrosers, suggesting two different speeds of liver fibrosis progression. ${ }^{85}$ Multivariate analysis identified donor age, bilirubin level, and LS as independent predictors of fibrosis progression and portal hypertension in the estimation group. ${ }^{85}$ Another study suggested that TE is a reliable tool to assess liver fibrosis in patients with recurrent $\mathrm{HCV}$ after living donor liver transplantation. ${ }^{86}$

Table 6 Liver stiffness and prediction of esophageal varices

\begin{tabular}{|c|c|c|c|c|c|c|c|}
\hline Patients & $\mathbf{n}$ & $\begin{array}{l}\text { Cut-off for } \\
\text { varices }\end{array}$ & AUROC & Sensitivity & Specificity & $\begin{array}{l}\text { PPVI } \\
\text { NPV }\end{array}$ & Ref. \\
\hline $\mathrm{HCV}$ & 65 & $17.6 \mathrm{kPa}$ & 0.76 & 0.9 & & & 69 \\
\hline Children with biliary atresia & 49 & $9.7 \mathrm{kPa}$ & & 0.97 & 0.8 & & 70 \\
\hline Cirrhosis & 165 & $19.5 \mathrm{kPa}$ & 0.83 & 0.84 & & $47 / 93$ & 71 \\
\hline $\begin{array}{l}\text { HBV LSM-spleen diameter } \\
\text { to platelet ratio score (LSPS) }\end{array}$ & 90 & & 0.95 & 0.947 & & & 72 \\
\hline $\mathrm{HCV}$ & & $21.5 \mathrm{kPa}$ & & 0.76 & 0.78 & & 54 \\
\hline $\begin{array}{l}\mathrm{HIV} / \mathrm{HCV} \text { coinfected patients } \\
\text { with liver cirrhosis }\end{array}$ & 102 & $21 \mathrm{kPa}$ & $0.7 \mathrm{I}$ & & & 100 & 73 \\
\hline
\end{tabular}

Abbreviations: $\mathrm{HCV}$, hepatitis C virus; HBV, hepatitis B virus; HIV, human immunodeficiency virus; ALD, alcoholic liver disease; NAFLD, nonalcoholic fatty liver disease; LS, liver stiffness; PBC, primary biliary cirrhosis; PSC, primary sclerosing cholangitis; AUROC, areas under receiver operating characteristic curves; PPV, positive predictive value; NPV, negative predictive value. 


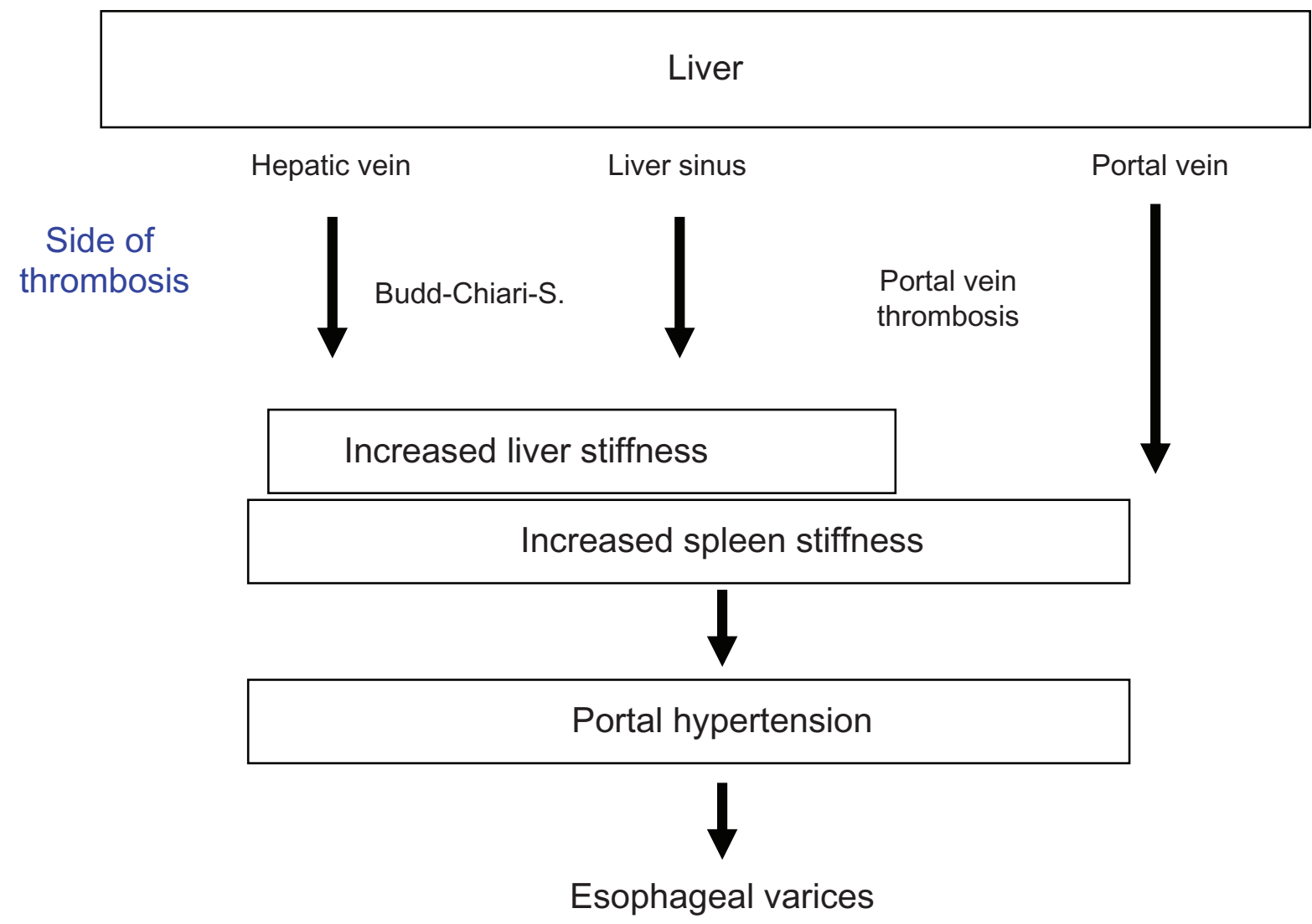

Figure 8 Liver stiffness is increased in post-sinusoidal thrombosis (eg, Budd-Chiari-Syndrome) but not in pre-sinusoidal thrombosis (eg, portal vein thrombosis). Additional measurement of spleen stiffness closes the diagnostic gap.

\section{Liver stiffness and hepatectomy}

Tactile stiffness sensors have been evaluated in the pre-FS era with success in patients with partial hepatectomy to predict the sufficient remain liver mass. ${ }^{87-89}$ It remains open whether FS will add to the evaluation of critical liver mass especially in fibrotic patients prior to partial hepatectomy.

\section{Present algorithm to diagnose liver disease via liver stiffness}

Various algorithms have been presented mainly for viral hepatitis to use LS in combination with blood tests to improve the noninvasive diagnosis of liver fibrosis or to spare at least some patients from the invasive liver biopsy. ${ }^{55,90}$ Given the many interfering factors that modulate LS, however, we are somewhat skeptical about using such approaches. Such statistical approaches aim to automate a complex diagnostic decision procedure. At the end, a unique patient requires an individual differential diagnosis, and a careful balance of the various risks has to be kept. Just to mention one example, many patients with viral hepatitis do have additional liver diseases such as alcoholic liver disease or suboptimal dietary condition. These are all factors that can dramatically worsen the outcome of chronic hepatitis in a synergistic manner. ${ }^{91}$ With this regard, at least to us, it is more useful to view LS

Table 7 Liver stiffness and portal hypertension by pre-and postsinusoidal thrombosis

\begin{tabular}{|c|c|c|c|c|}
\hline Thrombosis & Disease & Fibrosis & $\begin{array}{l}\text { Portal } \\
\text { hypertension }\end{array}$ & $\begin{array}{l}\text { Liver } \\
\text { stiffness }\end{array}$ \\
\hline Presinusoidal & $\begin{array}{l}\text { Portal vein thrombosis } \\
\text { Idiophatic portal } \\
\text { hypertension }\end{array}$ & $\begin{array}{l}\text { no } \\
\text { no }\end{array}$ & $\begin{array}{l}\text { yes } \\
\text { yes }\end{array}$ & $\begin{array}{l}\text { normal } \\
\text { normal, slightly } \\
\text { elevated }\end{array}$ \\
\hline $\begin{array}{l}\text { Sinusoidal } \\
\text { thrombosis }\end{array}$ & $\begin{array}{l}\text { hepatic veno-occlusive } \\
\text { disease (sinusoidal } \\
\text { obstruction syndrome) }\end{array}$ & yes & yes & elevated \\
\hline $\begin{array}{l}\text { Postsinusoidal } \\
\text { thrombosis }\end{array}$ & Budd-chiari syndrome & yes & yes & elevated \\
\hline
\end{tabular}


Table 8 Liver stiffness and risk of hepatocellular carcinoma

\begin{tabular}{|c|c|c|c|c|}
\hline Patients & $\mathbf{N}$ & Liver stiffness & HCC likelihood & Ref. \\
\hline \multirow[t]{5}{*}{$\mathrm{HCV}$} & 262 & $<10 \mathrm{kPa}$ & 0.22 & 82 \\
\hline & & 10.1 to $15 \mathrm{kPa}$ & 0.73 & \\
\hline & & I5.I to $25 \mathrm{kPa}$ & 1.3 & \\
\hline & & $>25 \mathrm{kPa}$ & 5.0 & \\
\hline & & & (stratum-specific likelihood ratios) & \\
\hline \multirow[t]{6}{*}{ HCV, prosepctive study } & 984 & $10.1-15 \mathrm{kPa}$ & 16.7 & 83 \\
\hline & & I5. I-20 kPa & 20.9 & \\
\hline & & 20. $\mathrm{I}-25 \mathrm{kPa}>25 \mathrm{kPa}$ & 25.6 & \\
\hline & & & 45.5 & \\
\hline & & & (hazard ratio, as compared & \\
\hline & & & to $L S M \leq 10 \mathrm{kPa})$ & \\
\hline \multirow[t]{3}{*}{ HCV, ALD } & 265 & & Patients with $\mathrm{HCC}$ had higher & 84 \\
\hline & & & LS than patients without $\mathrm{HCC}$; & \\
\hline & & & 35.3 vs $19.0 \mathrm{kPa}$ & \\
\hline HBV LSM-spleen diameter & 90 & & 0.95 & 72 \\
\hline \multicolumn{5}{|l|}{ to platelet ratio score (LSPS) } \\
\hline $\mathrm{HCV}$ & & $21.5 \mathrm{kPa}$ & & 54 \\
\hline HIV/HCV-coinfected patients & 102 & $21 \mathrm{kPa}$ & 0.71 & 73 \\
\hline with liver cirrhosis & & & & \\
\hline
\end{tabular}

Abbreviations: HCV, hepatitis C virus; ALD, alcoholic liver disease; HBV, hepatitis B virus; HIV, human immunodeficiency virus; LS, liver stiffness; HCC, hepatocellular carcinoma.

as a novel physical parameter such as, for example, body temperature - which can be objectively measured and should then be interpreted in the full clinical context. We propose this more open and critical procedure since misinterpretations or biases can rapidly harm the patient and delay other important diagnostic or therapeutic measures.

A general actual scheme for the interpretation of LS is shown in Figure 9.

Although, the definition of normal stiffness values are still under discussion and need to be defined for various populations with regard to age, gender, or other factors, recent populations of healthy blood donors or the influence of position changes and breath maneuvers suggest an LS $<6 \mathrm{kPa}$ as normal. ${ }^{23,24}$ Moreover, at least in our experience, an LS $<6 \mathrm{kPa}$ seems to exclude any manifest liver disease since all potential confounding factors such as inflammation, cholestasis or congestion increase LS. LS measurements are therefore an ideal screening tool to exclude any severe ongoing liver disease. Of course, one should be aware that other pathological conditions such as fatty liver or even terminal liver failure do not increase LS further, or may even decrease LS, but these conditions are easily discernible within the clinical context. If LS is higher than $6 \mathrm{kPa}$ an ultrasound is required to exclude mechanic cholestasis ${ }^{61}$ liver congestion ${ }^{30}$ or nodular masses.

Typically, we obtain the ultrasound before stiffness measurements since other valuable information such as splenomegaly, ascites or signs of liver disease can be detected. In addition, the location of an optimal stiffness measurement is identified. Thus, it becomes rapidly clear that a valid interpretation of LS is only possible in association with a qualified abdominal ultrasound.

If ultrasound does not reveal any of the stiffnessmodulating factors above, serum transaminases should be obtained. If the serum transaminases are normal, LS can be directly used to quantitate the degree of fibrosis. If the serum transaminases, mainly AST, are below $100 \mathrm{U} / \mathrm{L}$, the diagnosis of F4 fibrosis is highly accurate while F3 fibrosis should be viewed with caution. At AST levels higher than $100 \mathrm{U} / \mathrm{L}$, an accurate determination of fibrosis stage is not possible. It should be mentioned that these transaminase cut-off values have been obtained for patients with $\mathrm{ALD}^{40}$ and future studies are required to determine the conditions for other liver diseases.

The context-related interpretation of LS is more difficult in the case of several stiffness-related factors such as inflammation/fibrosis or liver congestion/cardiac cirrhosis. However, under certain conditions, a decision is still possible. For instance, in the case of ALD, the diagnosis of F4 cirrhosis can be made at LS $>24 \mathrm{kPa}$ despite ongoing severe alcoholic steatohepatitis. ${ }^{40}$ Such upper cut-off values need to be confirmed and defined for all other liver diseases in larger populations (see Figure 9). In addition, if possible, therapeutic interventions may help to more accurately differentiate fibrosis stage from other LS-increasing confounding factors. Thus, if liver congestion in a patient with congestive heart failure can be clearly cured by therapy with diuretics 


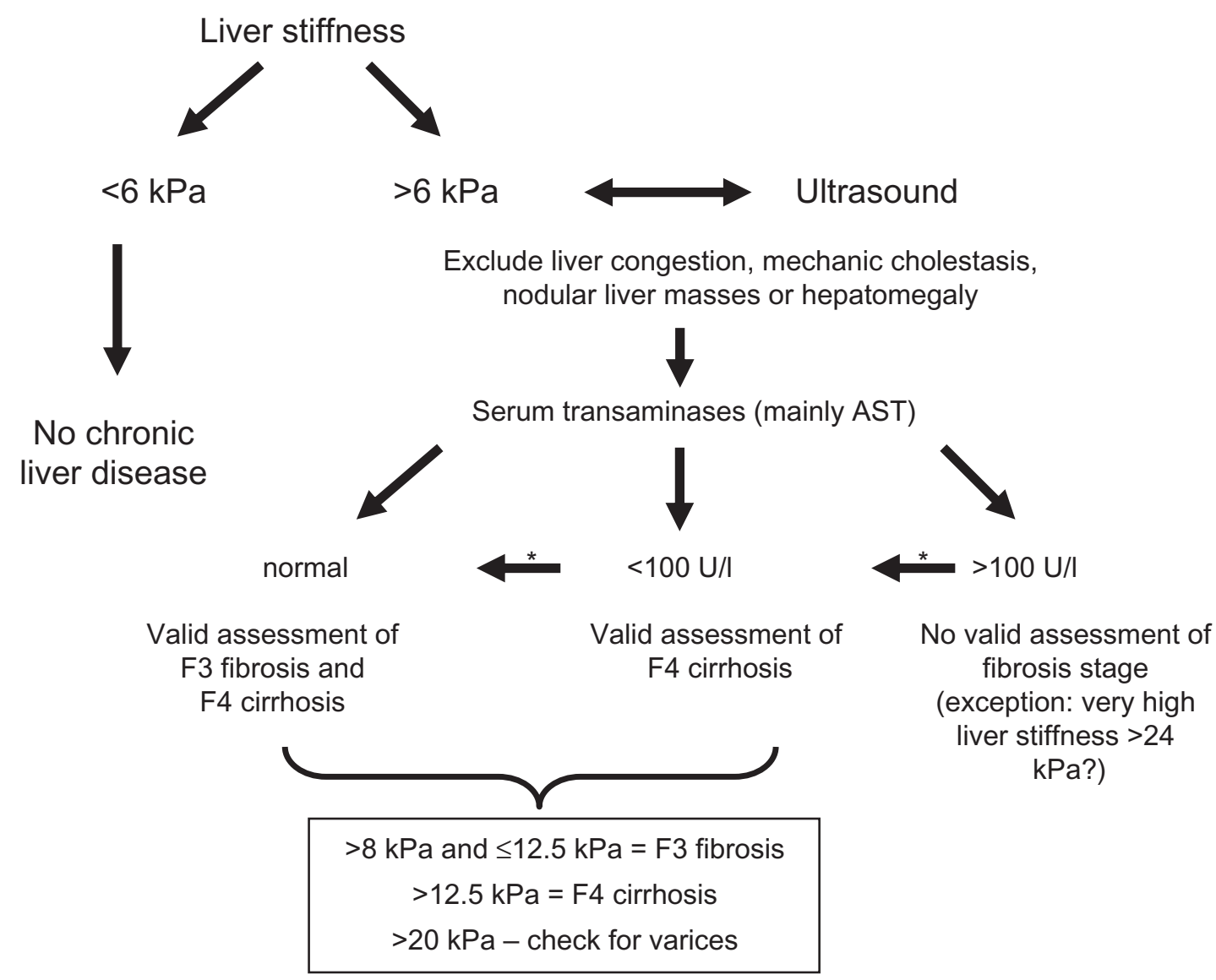

Figure 9 Estimated increase of liver stiffness by various clinical conditions irrespective of fibrosis.

Note: *alcohol withdrawal.

(as confirmed by ultrasound and blood tests), an increased but stable LS could directly be used to quantitate fibrosis stage. Under certain circumstances it is possible to estimate the contribution of venous pressure, mechanic cholestasis and inflammation (hepatitis). Figure 10 gives typical empirical values for stiffness changes as obtained from previous reports. ${ }^{30,40,61}$ Thus, during mechanic cholestasis by gallstones, an increase of bilirubin by $1 \mathrm{mg} / \mathrm{dl}$ will cause a medium increase in LS by ca. $1 \mathrm{kPa}$.

\section{Liver stiffness as molecular mechanism of liver fibrosis}

The molecular mechanisms of liver fibrosis are poorly understood despite extensive research activities over many decades. ${ }^{92-94}$ Consequently, no targeted treatment options exist to directly prevent progression of matrix deposition. It is intriguing that all chronic liver diseases eventually lead to liver cirrhosis and the sequence of steatosis, steatohepatitis and fibrosis/cirrhosis is generally accepted as causative. However, it is not known which of the intermediated steps are just bystanders or obligatory. In fact, most, if not all, liver diseases show various forms of inflammation and steatosis. It is also notable that in most scenarios, eg, ALD or $\mathrm{HCV}$, only a minority of patients (ca. 15\%) progress to cirrhosis. ${ }^{91}$ This generates some optimism that there are genetic or environmental causes that determine fibrosis progression and that fibrosis progression is not an essential and constitutional process. This optimism is further nourished by the established knowledge that early causative treatment of liver diseases not only stops fibrosis progression but can even introduce the complete reversal of fibrosis. Unfortunately, the conditions that define the "points of no return" are not known.

LS and its direct relation to pressure ${ }^{30,61}$ may serve as an eye-opener for mechanical stretch as a longtime neglected potential stimulus of matrix deposition. It is indeed fascinating to see that all possible conditions of liver cirrhosis increase LS, and that these conditions are not always related to inflammation (which is typically regarded as a common road to liver fibrosis of all liver diseases). Thus, mechanical stop of bile flow or hepatic vein blood flow dramatically increase LS, and both conditions are known to cause cirrhosis. Both conditions increase hydrostatic pressure in distinct compartments and ultimately lead to specific cirrhosis patterns (cardiac cirrhosis, 


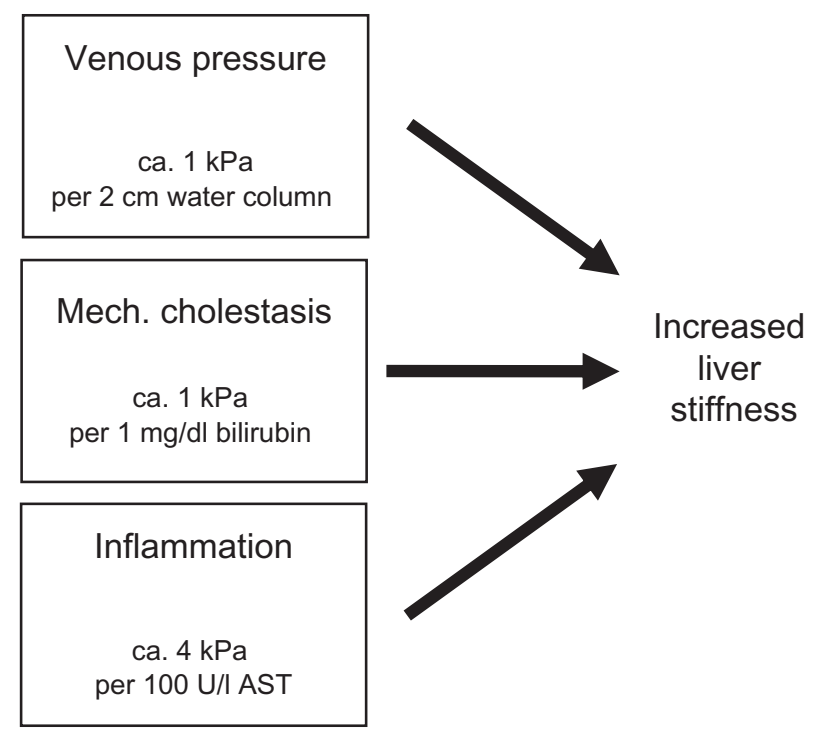

Figure 10 Present diagnostic algorithm of liver stiffness. For details see text. *Arrows indicate cured hepatitis eg, detoxification from alcohol or cure from hepatitis $C$ virus.

biliary fibrosis). Although both conditions may also lead to remarkable signs of inflammation or hepatocellular necrosis, they are typically not as pronounced as compared to inflammatory liver diseases such as ALD or viral hepatitis. On the other hand, it has become clear that inflammatory conditions increase LS irrespective of fibrosis. ${ }^{57,58}$ This is not a surprise since "tumor" (swelling) has been known since the ancient times as a classical sign of inflammation besides "calor" (heat), functio laesa and "rubor" (reddening). It is, however, undisputable that inflammation-caused tissue swelling regardless of its multifactorial cause, is also caused by pressure that is more related to osmotic pressure. Thus, in fact, all conditions that ultimately lead to cirrhosis cause increased LS, and this increased LS is initially related to increased pressure of various origins and in various compartments. It is very obvious that matrix and connective tissue are in balance with various kinds of pressures.

These observations and thoughts yield to the following new paradigm that we would like to call pressure-stiffness-fibrosis sequence hypothesis (see Figure 11): during chronic liver diseases, the accumulation of interstitial liquid and inflammatory infiltrate yield to an increase of local stress and stretch of blood vessels or bile ducts. Therefore, increased mechanical stretch would stimulate the production of collagen (fibrotic tissue) which would result in a permanent stiffness increase as if the liver was adapting its structure to mechanical conditions. Interestingly, increased LS values related to fibrotic tissue could be a long-term consequence of a short-term stiffness increase due to the inflammatory episode related to the chronic liver diseases. Portal hypertension would then be the consequence of increased vascular resistance either caused by inflammation or matrix-related increase of stiffness. Indeed, an increased rate of esophageal variceal bleeding is observed in patients with ALD in the phase of fulminant alcoholic steatohepatitis and in the absence of end stage cirrhosis, and these patients are known to reach high but reversible LS values.

Some very recent molecular findings may support the pressure-matrix-stiffness sequence hypothesis. Thus, mechanical stretch induces transforming growth factor (TGF)- $\beta$ synthesis in hepatic stellate cells, which is known to be highly expressed under profibrogenic conditions. ${ }^{95}$ From animal experiments it was recently concluded that increases in LS precede fibrosis and potentially myofibroblast activation. ${ }^{96}$ Thus, matrix stiffness could be a major denominator of the equilibrium of matrix-bound growth factors. ${ }^{97,98}$ These findings point to a regulatory interlink between physical forces of gravity, hemodynamic stress, and movement in tissue development that are still a poorly understood area of research. ${ }^{99}$ Intercellular mechanical coupling of stress fibres via adherens junctions, intracellular calcium oscillations, and mechanosensitive ion channels have been discussed to control cell-dense tissue by coordinating the activity of myofibroblasts. ${ }^{100}$ The pressure-matrix-stiffness hypothesis would also encourage a more in-depth look into the regulation of cell volume ${ }^{101,102}$ and aquaporin regulation. ${ }^{103}$ In addition, also a relation to vasoactive hormones such as natriuretic peptides seems to be attractive which are increased in all patients with edematous disorders which lead to an increase in atrial tension or central blood volume, such as renal failure or liver cirrhosis with ascites. ${ }^{104}$ Indeed, continuous intravenous infusion of atrial natriuretic peptide prevented liver fibrosis in rat. ${ }^{105}$

\section{Liver stiffness and future perspectives}

The noninvasive ability to measure LS has opened a new realm for both the diagnosis but also the molecular understanding of liver fibrosis. We will observe a rapid technical improvement of ultrasound and MRI-based elastography techniques. In addition, stiffness measurements of other organs such as spleen, pancreas or kidney will be possible. Hopefully, miniaturization will open stiffness measurements via endoscopic procedures. Modified technologies such as FS will be able to quantitate the degree for liver steatosis. Thus, a novel physical parameter has been developed to quantify hepatic steatosis. This VCTE-based ultrasonic attenuation is called 'CAP', for 'controlled attenuation parameter' and demonstrates good 


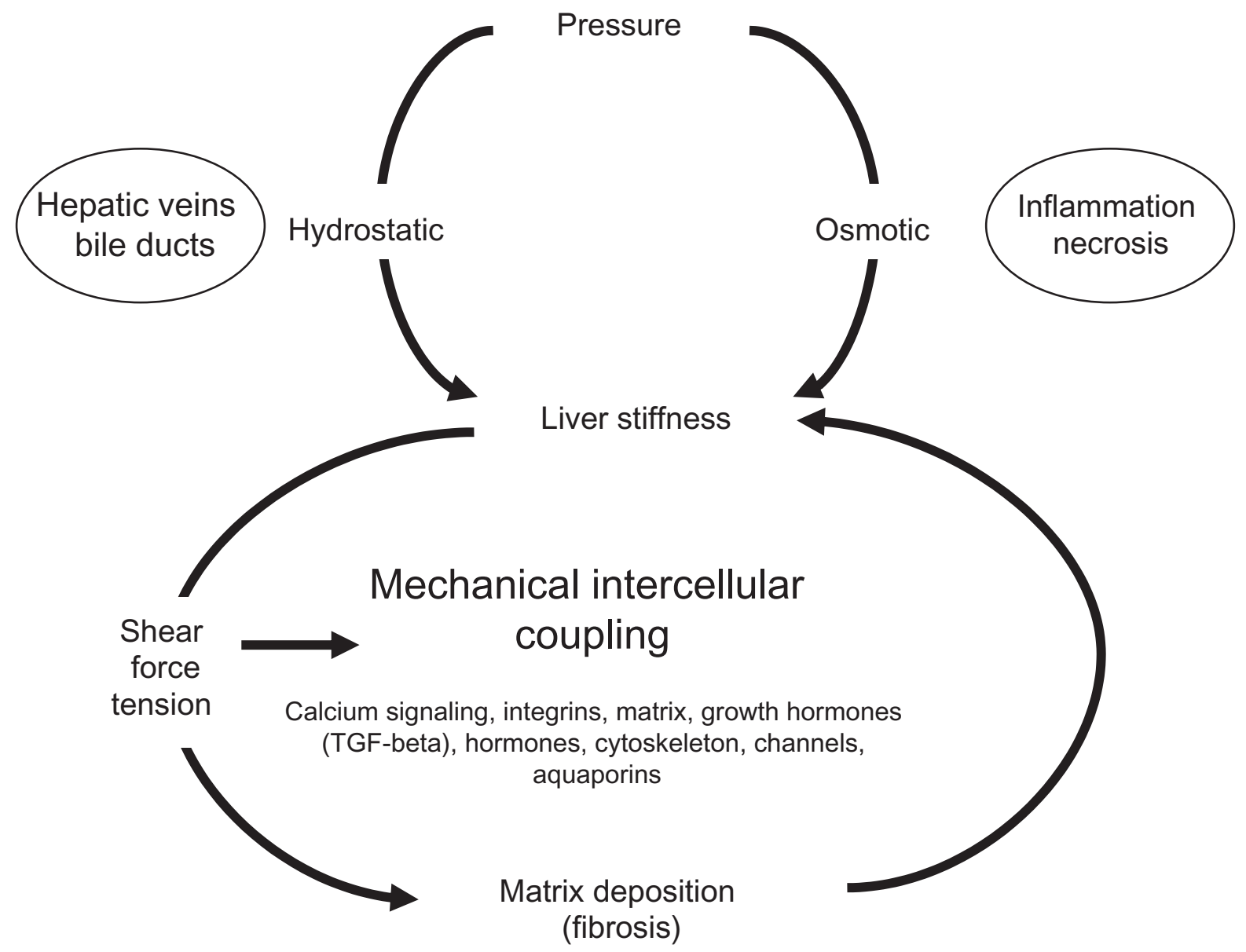

Figure II Pressure-stiffness-matrix sequence hypothesis. Either hydrostatic (venous or bile) or osmotic (eg, inflammation) pressure increases liver stiffness which, in turn, initiates increased matrix deposition via mechanical intercellular signaling. Matrix deposition finally leads to an irreversible increase of liver stiffness that is independent of pressure. These events may ultimately enter a vicious cycle causing end-stage liver disease. For more details see text.

performance for diagnosis of fatty infiltration in more than $10 \%$ of hepatocytes. ${ }^{106}$ With regards to LS, upcoming studies have to clarify the following open questions:

- Can we identify a direct quantitative relation between type and histological localization of hepatitis, serum transaminases and LS?

- What is the diagnostic value of LS in more complex clinical settings, eg, a patient with combined alcoholic liver fibrosis, steatohepatitis, and cardiomyopathy?

- Could LS be part of prognostic scores for patients on the liver transplantation waiting list?

- What other factors or rare diseases increase LS?

- Could we use LS as a novel parameter to measure venous pressure in the context of intensive care settings or cardiology?

- How valuable is LS in the neonatal screening for inborn liver diseases?

- What are the gender and age specific normal stiffness values?
- What are the population-wide prevalence rates of inceased LS and fibrosis?

The area of LS will booster many basic research activities, and novel miniaturized equipment is urgently required that will allow LS measurements on small animals such as mice. These are some of the questions that need to be addressed in the future:

- What are the genetic and molecular determinants of LS?

- What are the kinetics of LS in various fibrosis models?

- What are the kinetics of stiffness resolution in these models and is there a point of no return?

- Is there a critical cut-off value for stiffness that causes fibrosis?

- What is the role of vasoactive hormones, mechanosensing channels, and water channels such as aquaporins on LS and fibrosis?

- Are there pharmacological or other therapeutic approaches to modulate LS and treat liver fibrosis? 


\section{Acknowledgments}

This work was supported by the Dietmar-Hopp foundation and the Manfred-Lautenschläger Foundation. The authors are grateful to Professor Richard Ehman from the Mayo Clinic (Rochester, USA) for the very stimulating discussions.

\section{Disclosures}

SM reports no conflict of interest. LS developed VCTE (Fibroscan) and is currently Director of Research and Development at Echosens.

\section{References}

1. Bravo AA, Sheth SG, Chopra S. Liver biopsy. $N$ Engl J Med. 2001;344(7):495-500.

2. Abdi W, Millan JC, Mezey E. Sampling variability on percutaneous liver biopsy. Arch Intern Med. 139(6):667-669.

3. Bedossa P, Dargere D, Paradis V. Sampling variability of liver fibrosis in chronic hepatitis C. Hepatology. 2003;38(6):1449-1457.

4. Cadranel JF, Rufat P, Degos F. Practices of liver biopsy in France: results of a prospective nationwide survey. For the Group of Epidemiology of the French Association for the Study of the Liver (AFEF). Hepatology. 2000;32(3):477-481.

5. Maharaj B, Maharaj RJ, Leary WP, et al. Sampling variability and its influence on the diagnostic yield of percutaneous needle biopsy of the liver. Lancet. 1986;1(8480):523-525.

6. Regev A, Berho M, Jeffers LJ, et al. Sampling error and intraobserver variation in liver biopsy in patients with chronic $\mathrm{HCV}$ infection. Am J Gastroenterol. 2002;97(10):2614-2618.

7. Schuppan D, Afdhal NH. Liver cirrhosis. Lancet. 2008;371(9615): 838-851.

8. Sandrin L, Fourquet B, Hasquenoph JM, et al. Transient elastography: a new noninvasive method for assessment of hepatic fibrosis. Ultrasound Med Biol. 2003;29(12):1705-1713.

9. Muthupillai R, Lomas DJ, Rossman PJ, Greenleaf JF, Manduca A, Ehman RL. Magnetic resonance elastography by direct visualization of propagating acoustic strain waves. Science. 1995;269(5232): 1854-1857.

10. Rouviere O, Yin M, Dresner MA, et al. MR elastography of the liver: preliminary results. Radiology. 2006;240(2):440-448.

11. Klatt D, Asbach P, Rump J, et al. In vivo determination of hepatic stiffness using steady-state free precession magnetic resonance elastography. Invest Radiol. 2006;41(12):841-848.

12. Oudry J, Chen J, Glaser KJ, et al. Cross-validation of magnetic resonance elastography and ultrasound-based transient elastography: a preliminary phantom study. J Magn Reson Imaging. 2009;30(5):1145-1150

13. Bensamoun SF, Wang L, Robert L, Charleux F, Latrive JP, Ho Ba Tho MC. Measurement of liver stiffness with two imaging techniques: magnetic resonance elastography and ultrasound elastometry. J Magn Reson Imaging. 2008;28(5):1287-1292.

14. Yin M, Woollard J, Wang X, et al. Quantitative assessment of hepatic fibrosis in an animal model with magnetic resonance elastography. Magn Reson Med. 2007;58(2):346-353.

16. Palmeri ML, Wang MH, Dahl JJ, et al. Quantifying hepatic shear modulus in vivo using acoustic radiation force. Ultrasound Med Biol. 2008;34(4):546-558.

17. Muller M, Gennisson JL, Deffieux T, Tanter M, Fink M. Quantitative viscoelasticity mapping of human liver using supersonic shear imaging: preliminary in vivo feasibility study. Ultrasound Med Biol. 2009;35(2):219-229.

18. Bercoff J, Tanter M, Muller M, Fink M. The role of viscosity in the impulse diffraction field of elastic waves induced by the acoustic radiation force. IEEE Trans Ultrason Ferroelectr Freq Control. 2004;51(11):1523-1536.
19. Sarvazyan AP, Rudenko OV, Swanson SD, Fowlkes JB, Emelianov SY. Shear wave elasticity imaging: a new ultrasonic technology of medical diagnostics. Ultrasound Med Biol. 1998;24(9):1419-1435.

20. Hsu SJ, Liu CH, Kao JH, Chen DS. Acoustic radiation force impulse imaging predicts advanced fibrosis and cirrhosis in chronic hepatitis C patients. Hepatology. 2009;50(4):1623.

21. Saito H, Ebinuma H, Ojiro K, et al. Efficacy of liver stiffnes measurement using acoustic radiation force impulse in comparison with FibroScan. Hepatology. 2009;50(4):929.

22. Boursier J, Vergniol J, Sawadogo A, et al. The combination of a blood test and FibroScan improves the non-invasive diagnosis of liver fibrosis. Liver Int. 2009;29(10):1507-1515.

23. Adolf S, Millonig G, Friedrich S, Seitz HK, Mueller S. Valsalva and orthostatic maneuvers increase LS in healthy volunteers. Z Gastroenterol. 2010;48:1.

24. Colombo S, Belloli L, Buonocore M, et al. True normal liver stiffness measurement (LSM) and its determinants. Hepatology. 2009;50(4):927.

25. Kettaneh A, Marcellin P, Douvin C, et al. Features associated with success rate and performance of FibroScan measurements for the diagnosis of cirrhosis in HCV patients: a prospective study of 935 patients. J Hepatol. 2007;46(4):628-634.

26. Colletta C, Smirne C, Fabris C, et al. Value of two noninvasive methods to detect progression of fibrosis among $\mathrm{HCV}$ carriers with normal aminotransferases. Hepatology. 2005;42(4):838-845.

27. Nahon P, Thabut G, Ziol M, et al. LS measurement versus clinicians' prediction or both for the assessment of liver fibrosis in patients with chronic hepatitis C. Am J Gastroenterol. 2006;101(12):2744-2751.

28. Kim SU, Kim JK, Park JY, et al. Variability in liver stiffness values from different intercostal spaces. Liver Int. 2009;29(5):760-766.

29. Foucher J, Castera L, Bernard PH, et al. Prevalence and factors associated with failure of liver stiffness measurement using FibroScan in a prospective study of 2114 examinations. Eur J Gastroenterol Hepatol. 2006;18(4):411-412.

30. Millonig G, Friedrich S, Adolf S, et al. Liver stiffness is directly influenced by central venous pressure. J Hepatol. 2010;52(2): 206-210

31. Erhardt A, Lorke J, Vogt C, et al. Transient elastography for diagnosing liver cirrhosis. Dtsch Med Wochenschr. 2006;131(49):2765-2769.

32. Castera L, Vergniol J, Foucher J, et al. Prospective comparison of transient elastography, Fibrotest, APRI, and liver biopsy for the assessment of fibrosis in chronic hepatitis C. Gastroenterology. 2005;128(2):343-350.

33. Ganne-Carrie N, Ziol M, de Ledinghen V, et al. Accuracy of liver stiffness measurement for the diagnosis of cirrhosis in patients with chronic liver diseases. Hepatology. 2006;44(6):1511-1517.

34. Friedrich-Rust M, Ong MF, Martens S, et al. Performance of transient elastography for the staging of liver fibrosis: a meta-analysis. Gastroenterology. 2008;134(4):960-974.

35. Nguyen-Khac E, Chatelain D, Tramier B, et al. Assessment of asymptomatic liver fibrosis in alcoholic patients using FibroScan: prospective comparison with seven non-invasive laboratory tests. Aliment Pharmacol Ther. 2008; Aug 14 [Epub before print].

36. Nahon P, Kettaneh A, Tengher-Barna I, et al. Assessment of liver fibrosis using transient elastography in patients with alcoholic liver disease. J Hepatol. 2008;49(6):1062-1068.

37. de Ledinghen V, Douvin C, Kettaneh A, et al. Diagnosis of hepatic fibrosis and cirrhosis by transient elastography in HIV/ hepatitis C virus-coinfected patients. J Acquir Immune Defic Syndr. 2006;41(2):175-179.

38. Nguyen-Khac E, Chatelain D, Tramier B, et al. Assessment of asymptomatic liver fibrosis in alcoholic patients using FibroScan: prospective comparison with seven non-invasive laboratory tests. Aliment Pharmacol Ther. 2008;28(10):1188-1198.

39. Kim SG, Kim YS, Jung SW, et al. The usefulness of transient elastography to diagnose cirrhosis in patients with alcoholic liver disease. Korean J Hepatol. 2009;15(1):42-51. 
40. Mueller S, Millonig G, Sarovska L, et al. Increased liver stiffness in alcoholic liver disease: differentiating fibrosis from steatohepatitis. World J Gastroenterol. 2010;16(8):966-972.

41. Friedrich-Rust M, Müller C, Winckler A, et al. Assessment of liver fibrosis and steatosis in PBC With FibroScan, MRI, MR-spectroscopy, and serum markers. J Clin Gastroenterol. 2010;44(1):58-65.

42. Corpechot C, El Naggar A, et al. Assessment of biliary fibrosis by transient elastography in patients with PBC and PSC. Hepatology. 2006;43(5):1118-1124.

43. Gomez-Dominguez E, Mendoza J, Garcia-Buey L, et al. Transient elastography to assess hepatic fibrosis in primary biliary cirrhosis. Aliment Pharmacol Ther. 2008;27(5):441-447.

44. Romanque P, Stickel F, Dufour JF. Disproportionally high results of transient elastography in patients with autoimmune hepatitis. Liver Int. 2008;28(8):1177-1178.

45. Anastasiou J, Alisa A, Virtue S, Portmann B, Murray-Lyon I, Williams R. Noninvasive markers of fibrosis and inflammation in clinical practice: prospective comparison with liver biopsy. Eur $J$ Gastroenterol Hepatol. 2010;22(4):474-480.

46. Tomeno W, Yoneda M, Nozaki Y, et al. Novel ultrasound-based acoustic radiation force elastography in patients with non-alcoholic fatty liver disease (NAFLD). Hepatology. 2009;50(4):1035.

47. Wong VW, Vergniol J, Wong GL, et al. Diagnosis of fibrosis and cirrhosis using liver stiffness measurement in nonalcoholic fatty liver disease. Hepatology. 2010;51(2):454-462.

48. Wang JH, Changchien CS, Hung CH, et al. FibroScan and ultrasonography in the prediction of hepatic fibrosis in patients with chronic viral hepatitis. J Gastroenterol. 2009;44(5):439-446.

49. Mueller S, Millonig G, Stickel F, Longerich T, Schirmacher P, Seitz HK. Improved diagnostic accuracy of transient elastography for cirrhosis using histology plus clinics as gold standard. Z Gastroenterol. 2010;48:1.

50. Coco B, Oliveri F, Maina AM, et al. Transient elastography: a new surrogate marker of liver fibrosis influenced by major changes of transaminases. J Viral Hepat. 2007;14(5):360-369.

51. Corradi F, Piscaglia F, Flori S, et al. Assessment of liver fibrosis in transplant recipients with recurrent $\mathrm{HCV}$ infection: usefulness of transient elastography. Dig Liver Dis. 2009;41:217-225. Epub 2008 Jul 29.

52. Friedrich-Rust M, Muller C, Winckler A, et al. Assessment of liver fibrosis and steatosis in PBC with FibroScan, MRI, MR-spectroscopy, and serum markers. J Clin Gastroenterol. 2010;44(1):58-65.

53. Salles N, Dussarat P, Foucher J, Villars S, de Ledinghen V. Noninvasive evaluation of liver fibrosis by transient elastography and biochemical markers in elderly inpatients. Gastroenterol Clin Biol. 2009;33(2):126-132.

54. Castera L, Bail BL, Roudot-Thoraval F, et al. Early detection in routine clinical practice of cirrhosis and oesophageal varices in chronic hepatitis $\mathrm{C}$ : comparison of transient elastography (FibroScan) with standard laboratory tests and non-invasive scores. J Hepatol. 2009;50(1):59-68.

55. Sebastiani G, Halfon P, Castera L, et al. SAFE biopsy: a validated method for large-scale staging of liver fibrosis in chronic hepatitis $\mathrm{C}$. Hepatology. 2009;49(6):1821-1827.

56. Wong VWS, Vergniol J, Wong GLH, et al. Diagnosis of fibrosis and cirrhosis using LIVER STIFFNESS measurement in nonalcoholic fatty liver disease. Hepatology. 2010;51(2):454-462.

57. Arena U, Vizzutti F, Corti G, et al. Acute viral hepatitis increases LIVER STIFFNESS values measured by transient elastography. Hepatology. 2008;47(2):380-384.

58. Sagir A, Erhardt A, Schmitt M, Haussinger D. Transient elastography is unreliable for detection of cirrhosis in patients with acute liver damage. Hepatology. 2008;47(2):592-595.

59. Chang J, Lui HF, Tan CK, Chow WC. Transient elastography (FibroScan) is reliable for non-invasive diagnosis of significant fibrosis in chronic hepatitis B with mild transaminases but becomes less reliable at higher ALT levels. Hepatology. 2009;50(4):414.
60. Calvaruso V, Camma C, Di Marco V, et al. Fibrosis staging in chronic hepatitis $\mathrm{C}$ : analysis of discordance between transient elastography and liver biopsy. J Viral Hepat. Epub 2009 Sept 25.

61. Millonig G, Reimann FM, Friedrich S, et al. Extrahepatic cholestasis increases LS (FibroScan) irrespective of fibrosis. Hepatology. 2008;48(5):1718-1723.

62. Sirli R, Sporea I, Tudora A, Deleanu A, Popescu A. Transient elastographic evaluation of subjects without known hepatic pathology: does age change the liver stiffness? J Gastrointestin Liver Dis. 2009;18(1):57-60.

63. Friedrich-Rust M, Koch C, Rentzsch A, et al. Noninvasive assessment of liver fibrosis in patients with Fontan circulation using transient elastography and biochemical fibrosis markers. J Thorac Cardiovasc Surg. 2008;135(3):560-567.

64. Kiesewetter CH, Sheron N, Vettukattill JJ, et al. Hepatic changes in the failing Fontan circulation. Heart. 2007;93(5):579-584.

65. Cypierre A, Jaccard A, Rousseau A, et al. FibroScan is a non-invasive tool for detecting hepatic amyloidosis. Hepatology. 2009;50(4):921.

66. Lanzi A, Gianstefani A, Mirarchi MG, Pini P, Conti F, Bolondi L. Liver AL amyloidosis as a possible cause of high liver stiffness values. Eur J Gastroenterol Hepatol. Epub 2009 Aug 20.

67. Carrion JA, Navasa M, Bosch J, Bruguera M, Gilabert R, Forns X. Transient elastography for diagnosis of advanced fibrosis and portal hypertension in patients with hepatitis $\mathrm{C}$ recurrence after liver transplantation. Liver Transpl. 2006;12(12):1791-1798.

68. Lemoine M, Katsahian S, Ziol M, et al. Liver stiffness measurement as a predictive tool of clinically significant portal hypertension in patients with compensated hepatitis $\mathrm{C}$ virus or alcohol-related cirrhosis. Aliment Pharmacol Ther. 2008;28(9):1102-1110.

69. Vizzutti F, Arena U, Romanelli RG, et al. Liver stiffness measurement predicts severe portal hypertension in patients with HCV-related cirrhosis. Hepatology. 2007;45(5):1290-1297.

70. Chang HK, Park YJ, Koh H, et al. Hepatic fibrosis scan for liver stiffness score measurement: a useful preendoscopic screening test for the detection of varices in postoperative patients with biliary atresia. J Pediatr Gastroenterol Nutr. 2009;49(3):323-328.

71. Kazemi F, Kettaneh A, N'Kontchou G, et al. LIVER STIFFNESS measurement selects patients with cirrhosis at risk of bearing large oesophageal varices. J Hepatol. 2006;45(2):230-235.

72. Kim BK, Han KH, Park JY, et al. A liver stiffness measurement-based, noninvasive prediction model for high-risk esophageal varices in B-viral liver cirrhosis. Am J Gastroenterol. 2010; Jan 19 [Epub ahead of print].

73. Pineda JA, Recio E, Camacho A, et al. Liver stiffness as a predictor of esophageal varices requiring therapy in HIV/hepatitis $\mathrm{C}$ viruscoinfected patients with cirrhosis. J Acquir Immune Defic Syndr. 2009;51(4):445-449.

74. Calvaruso V, Di Marco V, Bronte F, et al. Measurement of spleen stiffness by transient elastography increases the accuracy of detection of portal hypertension in HCV cirrhosis. Hepatology. 2009;50(4):1643.

75. Shrestha SM. Liver cirrhosis and hepatocellular carcinoma in hepatic vena cava disease, a liver disease caused by obstruction of inferior vena cava. Hepatol Int. 2009;3(2):392-402.

76. Robles-Medranda C, Lukashok H, Biccas B, Pannain VL, Fogaca HS. Budd-Chiari-like syndrome in decompensated alcoholic steatohepatitis and liver cirrhosis. World J Gastroenterol. 2006;12(40): 6564-6566.

77. Chang PE, Miquel R, Blanco JL, et al. Idiopathic portal hypertension in patients with HIV infection treated with highly active antiretroviral therapy. Am J Gastroenterol. 2009;104(7):1707-1714.

78. Vergniol J, Foucher J, Castera L, et al. Changes of non-invasive markers and FibroScan values during HCV treatment. J Viral Hepat. Epub 2008 Oct 17.

79. Ogawa E, Furusyo N, Toyoda K, Takeoka H, Maeda S, Hayashi J. The longitudinal quantitative assessment by transient elastography of chronic hepatitis $\mathrm{C}$ patients treated with pegylated interferon alpha- $2 \mathrm{~b}$ and ribavirin. Antiviral Res. 2009;83(2):127-134. 
80. Andersen ES, Moessner BK, Christensen PB, Kjaer MS, Weis N. Significant decline in LIVER STIFFNESS during four years of follow-up among patients cured for hepatitis C. Hepatology. 2009;50(4):213.

81. Foucher J, Chanteloup E, Vergniol J, et al. Diagnosis of cirrhosis by transient elastography (FibroScan): a prospective study. Gut. 2006;55(3):403-408.

82. Masuzaki R, Tateishi R, Yoshida H, et al. Risk assessment of hepatocellular carcinoma in chronic hepatitis $\mathrm{C}$ patients by transient elastography. J Clin Gastroenterol. 2008;42(7):839-843.

83. Masuzaki R, Tateishi R, Yoshida H, et al. Prospective risk assessment for hepatocellular carcinoma development in patients with chronic hepatitis $\mathrm{C}$ by transient elastography. Hepatology. 2009;49(6):1954-1961.

84. Nahon P, Kettaneh A, Lemoine M, et al. Liver stiffness measurement in patients with cirrhosis and hepatocellular carcinoma: a case-control study. Eur J Gastroenterol Hepatol. 2009;21(2):214-219.

85. Carrion JA, Torres F, Crespo G, et al. Liver stiffness identifies two different patterns of fibrosis progression in patients with hepatitis $\mathrm{C}$ virus recurrence after liver transplantation. Hepatology. 2010;51(1):23-34.

86. Harada N, Soejima Y, Taketomi A, et al. Assessment of graft fibrosis by transient elastography in patients with recurrent hepatitis $\mathrm{C}$ after living donor liver transplantation. Transplantation. 2008;85(1):69-74.

87. Kusaka K, Harihara Y, Torzilli G, et al. Objective evaluation of liver consistency to estimate hepatic fibrosis and functional reserve for hepatectomy. J Am Coll Surg. 2000;191(1):47-53.

88. Hatakeyama Y, Ono T, Sato N, et al. Usefulness of the tactile sensor for estimating the degree of liver fibrosis and the DNA synthesis activity of remnant liver cells after partial hepatectomy. Fukushima J Med Sci. 2002;48(2):93-101.

89. Kim SU, Ahn SH, et al. Prediction of postoperative hepatic insufficiency by liver stiffness measurement (FibroScan) before curative resection of hepatocellular carcinoma: a pilot study. Hepatol Int. 2008;2(4):471-477.

90. Chan HL, Wong GL, Choi PC, et al. Alanine aminotransferase-based algorithms of liver stiffness measurement by transient elastography (FibroScan) for liver fibrosis in chronic hepatitis B. J Viral Hepat. 2009; 16(1):36-44.

91. Mueller S, Millonig G, Seitz HK. Alcoholic liver disease and hepatitis C: a frequently underestimated combination. World $J$ Gastroenterol. 2009;15(28):3462-3471.

92. Schuppan D, Ruehl M, Somasundaram R, Hahn EG. Matrix as a modulator of hepatic fibrogenesis. Semin Liver Dis. 2001;21(3):351-372.

93. Bataller R, Brenner DA. Liver fibrosis. J Clin Invest. 2005;115(2): 209-218.

94. Tsukada S, Parsons CJ, Rippe RA. Mechanisms of liver fibrosis. Clin Chim Acta. 2006;364(1-2):33-60.

95. Sakata R, Ueno T, Nakamura T, Ueno H, Sata M. Mechanical stretch induces TGF-beta synthesis in hepatic stellate cells. Eur J Clin Invest 2004;34(2):129-136.
96. Georges PC, Hui JJ, Gombos Z, et al. Increased stiffness of the rat liver precedes matrix deposition: implications for fibrosis. Am J Physiol Gastrointest Liver Physiol. 2007;293(6):G1147-G1154.

97. Buxboim A, Ivanovska IL, Discher DE. Matrix elasticity, cytoskeletal forces and physics of the nucleus: how deeply do cells 'feel' outside and in? J Cell Sci. 2010;123(Pt 3):297-308.

98. Wells RG, Discher DE. Matrix elasticity, cytoskeletal tension, and TGF-beta: the insoluble and soluble meet. Sci Signal. 2008; 1 (10): pe13.

99. Ingber DE. Tensegrity: the architectural basis of cellular mechanotransduction. Annu Rev Physiol. 1997;59:575-599.

100. Follonier L, Schaub S, Meister JJ, Hinz B. Myofibroblast communication is controlled by intercellular mechanical coupling. J Cell Sci. 2008;121(Pt 20):3305-3316

101. Haussinger D, Reinehr R, Schliess F. The hepatocyte integrin system and cell volume sensing. Acta Physiol (Oxf). 2006;187(1-2):249-255.

102. Haussinger D, Lang F. Cell volume and hormone action. Trends Pharmacol Sci. 1992;13(10):371-373.

103. Bienert GP, Moller AL, Kristiansen KA, et al. Specific aquaporins facilitate the diffusion of hydrogen peroxide across membranes. J Biol Chem. First published 2006 Nov 14. 2007;282:1183-1192.

104. Mair J, Hammerer-Lercher A, Puschendorf B. The impact of cardiac natriuretic peptide determination on the diagnosis and management of heart failure. Clin Chem Lab Med. 2001;39(7):571-588.

105. Ishigaki N, Yamamoto N, Jin H, Uchida K, Terai S, Sakaida I. Continuos intravenous infusion of atrial natriuretic peptide (ANP) prevented liver fibrosis in rat. Biochem Biophys Res Commun. 2009;378(3):354-359.

106. Beaugrand M, Ziol M, de Ledinghen V, et al. Novel ultrasonic FibroScan-based steatosis index for hepatic quantification in $618 \mathrm{HCV}$ patients. Hepatology. 2009;50(4):998.

107. Talwalkar JA, Yin M, Venkatesh S, et al. Feasibility of in vivo MR elastographic splenic stiffness measurements in the assessment of portal hypertension. Am J Roentgenol. 2009;193(1):122-127.

108. Gallotti A, D’Onofrio M, Pozzi Mucelli R. Acoustic Radiation Force Impulse (ARFI) technique in ultrasound with virtual touch tissue quantification of the upper abdomen. Radiol Med. Epub 2010 Jan 15.

109. Piscaglia F, Salvatore V, Borghi A, et al. Virtual touch assessment of liver stiffness: virtual liver palpation. Hepatology. 2009;50(4):1088.

110. Marcellin P, Ziol M, Bedossa P, et al. Non-invasive assessment of liver fibrosis by stiffness measurement in patients with chronic hepatitis B. Liver Int. 2009;29(2):242-247.

111. Fierbinteanu-Braticevici C, Andronescu D, Usvat R, Cretoiu D, Baicus C, Marinoschi G. Acoustic radiation force imaging sonoelastography for noninvasive staging of liver fibrosis. World $J$ Gastroenterol. 2009;15(44):5525-5532.

112. Bureau C, Metivier S, Peron JM, et al. Transient elastography accurately predicts presence of significant portal hypertension in patients with chronic liver disease. Aliment Pharmacol Ther. 2008;27(12) 1261-1268.
Hepatic Medicine: Evidence and Research

\section{Publish your work in this journal}

Hepatic Medicine: Evidence and Research is an international, peerreviewed, open access journal covering all aspects of adult and pediatric hepatology in the clinic and laboratory including the following topics: Pathology, pathophysiology of hepatic disease; Investigation and treatment of hepatic disease; Pharmacology of drugs used for

\section{Dovepress}

the treatment of hepatic disease. Issues of patient safety and quality of care will also be considered. The manuscript management system is completely online and includes a very quick and fair peer-review system, which is all easy to use. Visit http://www.dovepress.com/ testimonials.php to read real quotes from published authors. 